\title{
CONDITIONAL MARKET TIMING \\ WITH BENCHMARK INVESTORS
}

\author{
Connie Becker \\ Wayne Ferson \\ David Myers \\ Michael Schill
}

Working Paper 6434 
NBER WORKING PAPER SERIES

CONDITIONAL MARKET TIMING

WITH BENCHMARK INVESTORS

Connie Becker

Wayne Ferson

David Myers

Michael Schill

Working Paper 6434

http://www.nber.org/papers/w6434

\section{NATIONAL BUREAU OF ECONOMIC RESEARCH \\ 1050 Massachusetts Avenue \\ Cambridge, MA 02138 \\ February 1998}

We are grateful to Alan Hess, Peter Knez, Lawrence Kryzanowski, Anthony Lynch, Paul Malatesta, Ron Schoenberg, Rob Stambaugh, William Ziemba, an anonymous referee and seminar participants at the following universities for useful feedback: Chicago, Laval, Northwestern, Wharton and the University of Washington. This paper was also presented at the May, 1996 National Bureau of Economic Research Asset Pricing Program, the 1996 Northern Finance Association meetings, the 1996 Conference on Financial Economic and Accounting and the 1997 American Finance Association meetings. Ferson acknowledges financial support from the Pigott-Paccar professorship at the University of Washington. Any opinions expressed are those of the authors and not those of the National Bureau of Economic Research.

(C) 1998 by Connie Becker, Wayne Ferson, David Myers and Michael Schill. All rights reserved. Short sections of text, not to exceed two paragraphs, may be quoted without explicit permission provided that full credit, including $\odot$ notice, is given to the source. 
Conditional Market Timing with Benchmark Investors

Connie Becker, Wayne Ferson, David Myers

and Michael Schill

NBER Working Paper No. 6434

February 1998

JEL Nos. G11, G12, G14, G23

\section{ABSTRACT}

This paper tests models of mutual fund market timing that (1) allow the manager's utility function to depend on returns in excess of a benchmark; (2) distinguish timing based on lagged, publicly available information variables from timing based on finer information; and (3) simultaneously estimate the parameters which describe the public information environment, the risk aversion and the precision of the fund's market timing signal. Using a sample of more than 400 U.S. mutual funds for 1976-94, the estimates imply that mutual funds behave as risk averse, benchmark investors. Conditioning on public information variables improves the model specification, and after controlling for the public information we find no evidence that funds have significant market timing ability.

Connie Becker

Department of Finance and Business Economics

School of Business Administration

Box 353200

Seattle, WA 98195-3200

cbecker@u.washington.edu

David Myers

Department of Finance and Business Economics

School of Business Administration

Box 353200

Seattle, WA 98195-3200

hobson@u.washington.edu
Wayne Ferson

Department of Finance and Business Economics

School of Business Administration

Box 353200

Seattle, WA 98195-3200

and NBER

Michael Schill

Department of Finance and Business Economics

School of Business Administration

Box 353200

Seattle, WA 98195-3200

mjschill@u.washington.edu 


\section{Introduction}

Recent years have witnessed a rapid rise in the importance of mutual funds and other professionally-managed investment vehicles. There has been a corresponding flurry of research on the performance of managed funds and on techniques for measuring performance. One recent innovation is the conditional approach to performance evaluation, explored by Chen and Knez (1996) and Ferson and Schadt (1996). In a market-timing context, the idea is to distinguish timing behavior that merely reflects publicly available information, as captured by a set of instrumental variables, from timing based on better information. We call such informed timing ability conditional market timing. Ferson and Schadt estimate conditional versions of the classic market timing models of Treynor and Mazuy (1966) and Merton and Henriksson (1981). However, they examine a sample of equity mutual funds that are unlikely to aggressively time the market. The conditional timing ability of market-timing mutual funds therefore remains largely unexplored. ${ }^{1}$

This paper contributes to the literature on performance evaluation by further developing conditional market timing models. The models incorporate public information variables, similar to Ferson and Schadt (1996), in order to distinguish superior information from publicly available information signals. We also incorporate explicit performance benchmarks in the models. Such benchmarks are important in investment practice. For example, Schultz (1996) reports that Vanguard used incentive-based provisions in 24 of 38 compensation contracts with external fund managers. These contracts determine a manager's compensation by comparing the portfolio performance to that of a benchmark,

1 Harvey and Graham (1996) study conditional market timing information in U.S. investment newsletters, while Kryzanowski et al. (1996) study timing of macroeconomic variables by Canadian funds. 
typically the Standard and Poors 500 or some other specified index. Such incentive contracts induce a preference for portfolio return in excess of the benchmark.

Starks (1987) and Admati and Pfleiderer (1997) model incentive-based management contracts, focusing on agency problems between managers and investors. Malatesta (1992) and Brennan (1993) study the implications of benchmark investors for equilibrium asset pricing. Chiu and Roley (1992) and Brown, Harlow and Starks (1996) model fund manager behavior when relative performance is important. The importance of benchmarks for fund manager behavior is explicit or implicit in the empirical work of Golec (1992), Sirri and Tufano (1992), Chevalier and Ellison (1997) and others. Finally, Heinkel and Stoughton (1995) present market timing models with benchmark investors. They study unconditional models, and thus do not account for public information about future market returns. Ours is the first study to incorporate benchmark investors in a conditional market timing model.

We simultaneously estimate the parameters in the model describing the public information environment, the risk aversion of the fund and the precision of the fund's market timing signal. We are able to estimate the parameters under more general statistical assumptions than have been used in previous studies of market timing models.

Using a sample of more than 400 U.S. mutual funds for 1976-94, we find that both benchmark investing and conditioning information are important in the model. The estimates suggest that mutual funds behave as highly risk averse, benchmark investors. A cross-sectional analysis using actual holdings data suggests that the model parameters are informative about managers' portfolio strategies. Once we control for public information variables, there is little evidence that the mutual funds have market timing ability. 
The paper is organized as follows. Section 2 presents the models. Section 3 describes our empirical methods. Section 4 describes the data. Section 5 presents our empirical results, and section 6 offers concluding remarks.

\section{The Models}

We present a simple model of market timing in the spirit of Admati, et. al (1986). We imagine a manager who maximizes a single period utility function given a normally distributed private signal about the future market portfolio return. The signal is parameterized similar to Heinkel and Stoughton (1995), but modified for a conditional model as follows:

$$
S_{t}=K\left[r_{m t+1}-E\left(r_{m t+1} \mid Z_{t}\right)\right] / \sigma_{m}\left(1-R^{2}\right)^{1 / 2}+\epsilon_{t},
$$

where:

$r_{m t+1}=$ the future market excess return (net of a risk-free asset),

$E\left(r_{m t+1} \mid Z_{t}\right)=$ conditional expected excess return given $Z_{t}$, where

$\mathrm{Z}_{1}=$ a publicly available vector of information variables.

$R^{2}=$ the coefficient of determination, from a regression of $r_{m t+1}$ on $Z_{t}$,

$\sigma_{\mathrm{m}}=$ the unconditional standard deviation of the market return,

$\mathrm{K}=$ a parameter which captures the signal quality and

$\epsilon_{\mathrm{t}}=$ a normal $(0,1)$ disturbance term, independent of everything else in the model (except, of course, $S_{t}$ ).

Equation (1) defines the signal as information about the market that is independent of the public information, $Z_{t}$. We normalize the signal to have conditional mean zero. The 
parameter $\mathrm{K}$ measures the quality of the market timing signal. To interpret the parameter $\mathrm{K}$, consider the conditional correlation, $\rho$, between $S_{t}$ and the market return, given $\mathrm{Z}_{\mathrm{t}}$ :

$$
\rho=K /\left(1+K^{2}\right)^{1 / 2} .
$$

Thus, if $\mathrm{K}=0$ the manager has no more than public information and as $\mathrm{K}$ becomes large, the correlation approaches one. ${ }^{2}$ To better interpret the economic significance of the timing ability we report an estimate of the squared correlation $\rho^{2}$ from equation (2). A standard error for this estimate is computed using the delta method. ${ }^{3}$

The solution to the manager's portfolio problem depends on the conditional expected value and variance of the market return, given the information $\left(Z_{t}, S_{t}\right)$. Simple calculations give these moments as follows:

$$
\begin{aligned}
& E\left(r_{m t+1} \mid Z_{t}, S_{t}\right)=E\left(r_{m t+1} \mid Z_{t}\right)+S_{t} \sigma_{m}\left(1-R^{2}\right)^{1 / 2}\left[K /\left(1+K^{2}\right)\right] \\
& \operatorname{Var}\left(r_{m t+1} \mid Z_{t}, S_{t}\right)=\sigma_{m}^{2}\left(1-R^{2}\right) /\left(1+K^{2}\right) .
\end{aligned}
$$

\subsection{The Manager's Problem}

The portfolio manager is assumed to face a simple market timing problem; namely, the choice between a risky asset (say, the market portfolio, with return $R_{m}$ ) and a risk-free

2 Modelling the signal quality with the single parameter, $\mathrm{K}$, does not allow us to independently control the variance of the signal and its correlation with the market return. Experimenting with a more general signal structure, we were unable to identify empirically more than one parameter for the signal. This may not be surprising in view of our result that the market timing signals are rarely significant once we control for public information variables.

3 Given a point estimate of $\mathrm{K}$, a standard error $\sigma(\mathrm{K})$ and a functional form $p^{2}=$ $\mathrm{f}(\mathrm{K})$, the approximate standard error of $\rho^{2}$ according to the delta method is given by: $\left[\mathrm{f}^{\prime}(\mathrm{K})^{2} \sigma(\mathrm{K})^{2}\right]^{1 / 2}$, where $\mathrm{f}^{\prime}(\mathrm{K})$ is the derivative. 
asset with return $R_{f}$. The portfolio total return is $R_{p}=R_{f}+x r_{m}$, where $x$ is the control and $r_{m}=R_{m}-R_{f}$. The manager is assumed to maximize a utility function for returns in excess of a benchmark:

$$
E\left[u\left(R_{p}-\left\{h R_{m}+(1-h) R_{f}\right\}\right) \mid S, Z\right]
$$

where $u($.$) is a concave utility function and h$ is an exogenously-given parameter.

We refer to $h$ as the benchmark preference parameter. For values of $h$ between 0.0 and 1.0, the exogenous benchmark is a combination of $R_{m}$ and $R_{f}$, with a "policy weight" equal to $h$ on $R_{m}$ and (1-h) on cash. If $h=1$, the utility function argument is $R_{p}$ $R_{m}$, and the manager cares about the portfolio return relative to the "market" return, $R_{m}$. If $h=0$, the utility function argument is $R_{p}-R_{f}$, and the manager evaluates the portfolio return relative to the risk-free return on cash. Since the risk-free rate is a constant from the point of view of the manager, we interpret $h=0$ as the case where benchmark investing is irrelevant.

We take the existence of portfolio managers who are benchmark investors as a primitive model assumption, similar to Malatesta (1992) and Brennan (1993). In a more general model benchmark preferences should arise endogenously in a labor market equilibrium for portfolio managers. ${ }^{4}$

Differentiating equation (4) with respect to $\mathrm{x}$, setting the result equal to zero and using Stein's (1973) Lemma to express the covariance of the market with the marginal

4 Expressions similar to equation (5) appear in the model of Maug and Naik (1996), induced as a result of relative performance contracts. 
utility in terms of the covariance with the argument of the utility function, we derive the optimal portfolio weight in the risky asset as: ${ }^{5}$

$$
x=h+v^{-1} E\left(r_{m t+1} \mid Z_{t}, S_{t}\right) / \operatorname{Var}\left(r_{m t+1} \mid Z_{t}, S_{t}\right)
$$

where $\gamma$ is the Rubinstein (1973) measure of risk aversion, which we assume to be a fixed parameter. ${ }^{6}$

Equation (5) shows that when the manager's information indicates that the expected return of the market is equal to the risk-free rate, the manager holds the benchmark portfolio weight, h. As derived by Malatesta (1992) and Brennan (1993), a benchmark investor $(h \neq 0)$ treats the benchmark the way an investor without a benchmark $(\mathrm{h}=0)$ treats a risk-free asset. Given a positive expected excess return on the risky asset the manager puts more than the benchmark weight in the risky asset, the weight depending on the conditional variance and risk aversion. ${ }^{7}$ $\operatorname{Cov}(\mathrm{x}, \mathrm{y})$.

5 Stein's (1973) lemma implies that if $(\mathrm{x}, \mathrm{y}) \sim \mathrm{N}$, then: $\operatorname{Cov}(\mathrm{g}(\mathrm{x}), \mathrm{y})=\mathrm{E}\left\{\mathrm{g}^{\prime}(\mathrm{x})\right\}$

$6 y=-\mathrm{E}\left\{\mathrm{u}^{\prime \prime}() \mid. \mathrm{Z}, \mathrm{S}\right\} / \mathrm{E}\left\{\mathrm{u}^{\prime}() \mid. \mathrm{Z}, \mathrm{S}\right\}$.

7 The model can accommodate an error term in the expression for the weights, assuming the error is conditionally independent of $r_{m t+1}$, given $Z_{t}$. This allows for cross-sectional variation in the portfolio weights of managers who observe a common signal. Such an error may also be interpreted as capturing the security selection aspect of mutual fund behavior, discussed in section 5.6 below. Without such an error, our finding that the private signal quality parameter $\mathrm{K}$ is not significant implies an extreme form of "herding" in the model, where all managers respond in the same direction to a public signal about the future market return. (See Grinblatt, Titman and Wermers (1995) for a discussion of herding by mutual fund managers.) 
Malatesta (1992) and Brennan (1993) explore the equilibrium implications of a world in which some investors are benchmark investors, while others have $h=0$. Under some assumptions the original mean-variance CAPM [Sharpe (1964) or Black (1972)] can be obtained, but in general the presence of benchmark investors alters the equilibrium. In this paper we do not use a specific equilibrium model for expected returns. We simply assume that the portfolio manager is at an optimum as expressed by equation (5). ${ }^{8}$

A conventional wisdom among practitioners [e.g. Grinold and Kahn (1995)] holds that portfolio managers are highly risk averse to the deviation from a benchmark return. Our model captures this intuition. To see it use equation (5) and the fact that the portfolio excess return is $r_{p}=x_{m}$. Ignoring the conditioning information for simplicity, it follows that:

$$
\mathrm{E}\left(\mathrm{r}_{\mathrm{p}}\right) / \sigma^{2}\left(\mathrm{r}_{\mathrm{p}}\right)=\left[\mathrm{h}+\gamma^{-1} \mathrm{E}\left(\mathrm{r}_{\mathrm{m}}\right) / \sigma^{2}\left(\mathrm{r}_{\mathrm{m}}\right)\right]^{-1} \mathrm{E}\left(\mathrm{r}_{\mathrm{m}}\right) / \sigma^{2}\left(\mathrm{r}_{\mathrm{m}}\right) .
$$

Thus, if $h=0$ we have the standard result that $E\left(r_{p}\right) / \sigma^{2}\left(r_{p}\right)=\gamma$. Suppose that $\mathrm{E}\left(\mathrm{r}_{\mathrm{p}}\right) / \sigma^{2}\left(\mathrm{r}_{\mathrm{p}}\right)$ and $\mathrm{E}\left(\mathrm{r}_{\mathrm{m}}\right) / \sigma^{2}\left(\mathrm{r}_{\mathrm{m}}\right)$ are both in the conventional range, say approximately equal to 2.0. This would imply that benchmark investors are highly risk averse for deviations from the benchmark. In this example $h+2 / V \approx 1$, so if $h=0.8$ it implies $V \approx 10$, and if

8 We do implicitly assume that the incidence of managers with more information than $\mathrm{Z}$ is "small" enough to have no impact on market prices. Because the public can observe and condition on market prices, in some models prices could reveal the manager's signals [e.g. Grossman and Stiglitz (1980)]. Even in noisy rational expectations models with supply shocks or similar devices to prevent fully-revealing prices, the conditional distribution of returns given the observed prices may reflect some of the information of informed agents (see for example, the noisy rational expectations equilibrium of Admati and Ross (1985)). One can think of the public information vector $Z_{t}$ in our model as a sufficient statistic for the information of the "uninformed" agents who can observe market prices. 
$\mathrm{h}=0.9$ it implies $y \approx 20$. We therefore expect to find estimates of $y$ to be large, relative to conventional standards for measures of risk aversion.

\subsection{Empirical Models}

Equation (5) leads to an empirical model in the spirt of the unconditional models of Treynor and Mazuy (1966) and Admati, et. al (1986). The excess return at time $t+1$ is $r_{p t+1}=x_{t} r_{m t+1}$. Substituting from equation (5) for $x_{t}$ and using the expressions for the conditional moments from equation (3), we obtain:

$$
r_{p t+1}=h r_{m t+1}+Q_{0} E\left(r_{m t+1} \mid Z_{t}\right) r_{m t+1}+Q_{1} S_{t} r_{m t+1}
$$

where $\mathrm{Q}_{0}=\left[\gamma \sigma_{\mathrm{m}}{ }^{2}\left\{\left(1-\mathrm{R}^{2}\right) /\left(1+\mathrm{K}^{2}\right)\right\}\right]^{-1}$ and $\mathrm{Q}_{1}=\mathrm{K} /\left[V \sigma_{\mathrm{m}}\left(1-\mathrm{R}^{2}\right)^{1 / 2}\right]$. Now substitute the definition of $S_{t}$ into the above to obtain:

$$
\text { where } \quad \begin{aligned}
\mathrm{r}_{\mathrm{pt}+1}=h \mathrm{r}_{\mathrm{mt}+1}+\mathrm{Q}_{2} \mathrm{E}\left(\mathrm{r}_{\mathrm{mt}+1} \mid \mathrm{Z}_{\mathrm{t}}\right) \mathrm{r}_{\mathrm{mt}+1}+\mathrm{Q}_{3} \mathrm{r}_{\mathrm{mt}+1}^{2}+\mathrm{v}_{\mathrm{t}+1}, \\
\mathrm{Q}_{2}=1 /\left\{\gamma \sigma_{\mathrm{m}}^{2}\left(1-\mathrm{R}^{2}\right)\right\}, \\
\mathrm{Q}_{3}=\mathrm{K}^{2} /\left\{\gamma \sigma_{\mathrm{m}}^{2}\left(1-\mathrm{R}^{2}\right)\right\},
\end{aligned}
$$

and the error term is $v_{t+1}=Q_{1} \epsilon_{t+1} r_{m t+1}$. Note that, even under the assumption that $\left(\mathrm{r}_{\mathrm{mt}+1}, \mathrm{Z}_{\mathrm{t}}, \mathrm{S}_{\mathrm{t}}\right)$ are normally distributed, the nonlinearity induced by market timing implies that the error term of equation (7) is not normally distributed, even conditional on $Z_{\mathbf{t}}$. 
Normal, maximum likelihood methods would not be appropriate for estimating the model. ${ }^{9}$ Equation (7) refines the versions of the Treynor and Mazuy (1966) market timing model studied by Admati, et. al (1986) and Ferson and Schadt (1996). Admati, et. al discuss the separate estimation of risk aversion and signal quality but do not account for public information. Ferson and Schadt account for public information, but do not attempt to uncover the deeper structural parameters. Neither study explicitly accounts for benchmark investment behavior.

The model leads to specific hypotheses about the parameters in equation (7). The hypothesis that $\mathrm{K}=0$ says that the manager uses no market timing information beyond the publicly available instruments, $Z_{\mathrm{t}}$. If we find $\mathrm{K} \neq 0$, we interpret it as evidence of superior information. The hypothesis that $h=0$ says that the manager does not behave as a benchmark investor. If $h \neq 0$, the model delivers an estimate of the relevant benchmark as having policy weight $h$ in the index $R_{m}$, while the weight 1 -h is assigned to cash.

\subsection{Relation to Beta}

While the parameter $h$ in equation (7) is related to the beta of the fund, it differs from beta because the fund will vary its market exposure in response to both $Z_{t}$ and $S_{t}$. From equations (3) and (5), the conditional beta of the fund, given $Z_{t}$, may be derived as:

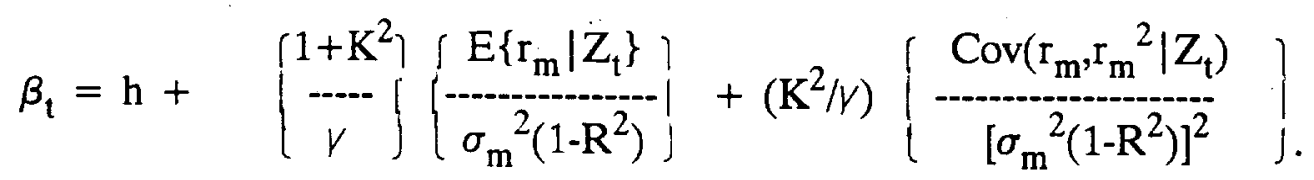

9 Conditional on $\left(\mathrm{Z}_{\mathrm{t}}, \mathrm{S}_{\mathrm{t}}\right)$ the portfolio return is normal. See Dybvig and Ross (1985) for a related discussion. 
The conditional beta depends on certain conditional moments of the market excess return and on the parameters $y$ and $\mathrm{K}$. Only when the two terms on the right hand side of equation (8) are zero, will the beta equal the parameter $h$. This situation occurs in the limit as risk aversion becomes infinite. With finite risk aversion the conditional beta varies over time as a function of the conditional expected premium on the market portfolio and the conditional skewness. If $\mathrm{K}=0$, the portfolio weight changes over time only in response to $Z_{t}$. In this case, the conditional beta is equal to the weight held by the fund in the market index [see equation (5)].

The unconditional beta can be shown to depend on the parameters $h, \gamma, \sigma_{\mathrm{m}}, \mathbf{R}^{2}$, $\mathrm{K}$ and on the moments $\operatorname{Cov}\left\{\mathrm{r}_{\mathrm{m}}{ }^{2}, \mathrm{r}_{\mathrm{m}}\right\}$ and $\operatorname{Cov}\left\{\mathrm{E}\left(\mathrm{r}_{\mathrm{m}} \mid \mathrm{Z}\right)^{2}, \mathrm{E}\left(\mathrm{r}_{\mathrm{m}} \mid \mathrm{Z}\right)\right\}$. As the risk aversion becomes infinite, the unconditional beta also approaches the parameter $h$.

\section{Econometric Methods}

In order to estimate the model, we use the functional form of the conditional mean of the market excess return, given the instruments $Z_{\mathrm{t}}$. Normality implies that the conditional mean is a linear regression function: $\mathrm{E}\left(\mathrm{r}_{\mathrm{mt}+1} \mid \mathrm{Z}_{\mathrm{t}}\right)=\delta_{0}+\mathrm{Z}_{\mathrm{t}}{ }^{\prime} \delta$, where $\delta$ is a slope coefficient vector. ${ }^{10}$ The econometric model includes a fund-specific "alpha" coefficient [see Jensen (19680]. The coefficient, $\alpha_{\mathrm{p}}$, captures "selectivity" aspects of performance that are not reflected in the model, and other forms of model misspecification on the levels of returns (see section 5.6).

10 Our model does not accommodate the possibility that market timers may know the relation between $Z_{t}$ and the future market return better than the general public understands the relation. A Bayesian analysis may allow such affects. 
The following system of moment conditions describes the econometric model. Each of the error terms has unconditional expected value equal to zero under the null hypothesis.

$$
\begin{aligned}
\mathrm{u} 1_{\mathrm{t}+1} & =\mathrm{r}_{\mathrm{mt}+1}-\mu_{\mathrm{m}} \\
\mathrm{u} 2_{\mathrm{t}+1} & =\sigma_{\mathrm{m}}{ }^{2}-\left(\mathrm{r}_{\mathrm{mt}+1}-\mu_{\mathrm{m}}\right)^{2} \\
\mathrm{u} 3_{\mathrm{t}+1} & =\left[\mathrm{r}_{\mathrm{mt}+1}-\delta_{0}-\mathrm{Z}_{\mathrm{t}}{ }^{\prime} \delta\right]\left(1, \mathrm{Z}_{\mathrm{t}}\right) \\
\mathrm{u} 4_{\mathrm{t}+1} & =\mathrm{R}^{2} \sigma_{\mathrm{m}}{ }^{2}-\left[\mu_{\mathrm{m}}-\delta_{0}-\mathrm{Z}_{\mathrm{t}} \delta^{2}\right]^{2} \\
\mathrm{u} 5_{\mathrm{pt}+1} & =\left[\mathrm{r}_{\mathrm{pt}+1}-\alpha_{\mathrm{p}}-\left(\mathrm{h}+\mathrm{Q}_{2} \delta_{0}\right) \mathrm{r}_{\mathrm{mt}+1}\right. \\
& \quad-\mathrm{Q}_{2}\left(\delta \mathrm{Z}_{\mathrm{t}} \mathrm{r}_{\mathrm{mt}+1}\right) \\
\quad & \left.\mathrm{Q}_{3} \mathrm{r}_{\mathrm{mt}+1}{ }^{2}\right]\left(1, \mathrm{Z}_{\mathrm{t}}, \mathrm{r}_{\mathrm{mt}+1}, \mathrm{r}_{\mathrm{mt}+1}{ }^{2}\right) .
\end{aligned}
$$

In the system (9), the first four equations identify the market-wide parameters $\sigma_{\mathrm{m}}, \delta_{0}, \delta$, $\mathrm{R}^{2}$ and the unconditional mean of the market excess return, $\mu_{\mathrm{m}}$. The expression for $\mathrm{u} 5_{\mathrm{pt}+1}$ corresponds to equation (7) and it identifies the fund-specific parameters of the model, $\alpha_{\mathrm{p}}, \mathrm{h}, \mathrm{K}^{2}$ and $\gamma\left(\mathrm{Q}_{2}\right.$ and $\mathrm{Q}_{3}$, as given by equation (7), are functions of these and the other model parameters).

We estimate the system (9) using the Generalized Method of Moments (GMM, Hansen, 1982). If $\mathrm{L}$ is the number of instruments in $Z_{t}$ (excluding the constant) and $N$ is the number of funds, then the number of moment conditions in the system (9) is $N(L+3)$ $+\mathrm{L}+4$. The number of parameters in the system is $4 \mathrm{~N}+\mathrm{L}+4$. Therefore, provided $\mathrm{L}>1$, the model is overidentified and may be tested using Hansen's J-statistic. Since all of the parameters of the system (9) are estimated simultaneously, we obtain consistent and 
asymptotically efficient GMM estimators, avoiding the two-step methods used in market timing models by Admati et. al, (1986), Coggin et al (1993) and Heinkel and Stoughton $(1995) .{ }^{11}$

\section{The Data}

\subsection{The Mutual Fund Returns}

We examine open-ended mutual fund returns from the Morningstar, Inc. OnDisc data base (quarterly, January 1993 through April 1995 versions). The returns data reflect the reinvestment of dividends and capital gains and are net of expenses, excepting front-end load charges and exit fees. We draw two samples of funds from the data base. The first is a broad sample of primarily U.S. equity funds, which are grouped by fund objective and investment style. The second is a set of U.S. asset allocation and balanced funds, which we denote as "asset allocators." We use this sample to study in more detail the kinds of funds that are relatively likely to engage in market timing activities.

For our first sample, we select funds with less than $20 \%$ of their holdings in nonU.S. stocks, at least $80 \%$ of their holdings in equity, and at least ten years of monthly returns available at the end of 1994. This results in a sample of 303 mutual funds. The time period is January, 1976 - December, 1994 (228 observations), and the number of

11 Define the error term $u_{t+1}$, by stacking up the errors $\left\{\mathrm{u} 1_{\mathrm{t}+1}, \mathrm{u} 2_{\mathrm{t}+1}, \mathrm{u} 3_{\mathrm{t}+1}, \mathrm{u} 4_{\mathrm{t}+1}, \mathrm{u} 5_{\mathrm{pt}+1}\right\}$ from the system $(9)$. The model implies $\mathrm{E}\left(\mathrm{u}_{\mathrm{t}+1}\right)=0$, where $E($.$) denotes the unconditional expectation The sample counterpart of the$ moment condition is $\mathrm{g}=\left[\mathrm{T}^{-1} \Sigma_{\mathrm{t}}\left(\mathrm{u}_{\mathrm{t}+1}\right)\right]$. Hansen (1982) shows that the GMM parameter estimates obtained by minimizing a quadratic form $\mathrm{g}^{\prime} \mathrm{Wg}$, where $\mathrm{W}$ is a fixed weighting matrix, are consistent and asymptotically normal. If $W$ is the inverse of a consistent estimate of the asymptotic covariance matrix of $\mathrm{g}$, then the GMM estimates are asymptotically efficient in the class of quadratic-form-minimizing estimators. 
funds with returns data increases over this period. Morningstar groups these funds according to two alternative criteria. The first is fund objective, and the second is investment "style." If such groupings are meaningful for investors, then our model implies that the parameters of interest $\left(\alpha, \gamma, \mathrm{K}^{2}, \mathrm{~h}\right)$ should differ across the groups. If the parameters are similar within groups, then working with the grouped funds may produce more precise estimates.

The first classification scheme uses the traditional self-reported investment objective of the mutual funds (e.g. aggressive growth, growth-income, etc.). Our sample includes eleven objectives. We form an equally-weighted portfolio of the funds with each stated objective. The portfolio return for each month is the equally-weighted average of all of the funds that fell into a given category and did not have a missing return for that month. ${ }^{12}$

Morningstar also classifies equity mutual funds according to investment "styles." Funds are ranked on the basis of the median value in their holdings, of the sum of the price/earnings ratio, measured relative to the average price/earnings ratio of stocks in the Standard and Poors 500, plus the market/book ratio, measured relative to the average market/book ratio of stocks in the Standard and Poors 500. The funds are then split into three groups (value, growth, or a "blend" of value and growth) on the basis of these rankings, where the break points are set by the corresponding ratios for the stocks in the Standard and Poors 500 index. A similar ranking is calculated, based on the market

12 The classifications by Morningstar are available to us for the ten quarters listed in panels $F$ and $G$ of Table 1 . We use the most recently-available previous quarter to assign funds to the categories for a given month. In the early part of the sample when the classifications are not available to us, we use data for the fourth quarter of 1992 . 
capitalization of the stocks held by the fund, and the result is a $3 \times 3$ classification of the funds according to investment style. We form nine equally-weighted portfolios corresponding to the investment styles, using the same procedure as for the objectivegrouped portfolios. Thus, we have two ways of grouping the same underlying sample of mutual funds into portfolios.

Our second sample of mutual funds is the asset allocators. We select funds with at least five years of monthly returns available at the end of March 1995. This results in a sample of 114 funds, of which 62 are classified as balanced funds and 52 are asset allocation funds.

Our samples of funds have a potential survivorship bias, as they contain only funds that survived until the end of the sample period. Survivorship may be expected to bias return performance upwards, relative to the universe of all mutual funds [e.g. Grinblatt and Titman (1988), Malkiel (1995)]. ${ }^{13}$ Survivorship can also lead to the apparent persistence of an attribute on which survival is conditioned (e.g. Brown, Goetzmann, Ibbotson and Ross, 1992). For example, if asset allocator funds that correctly call market moves by pure luck are more likely to survive, then in the surviving sample such "abilities" may appear to persist. It seems likely that such biases would produce a sample of asset allocator funds that appear better at market timing than would an unbiased sample. In view of these facts, our finding of no significant market timing ability is likely to hold up in a sample without selection biases.

Summary statistics for the portfolios of the equity funds are presented in Table 1.

13 Morningstar also back fills data, so funds that were not reported on older disks may appear on newer disks, with complete data. Selection biases may also lead to higher average returns. 
The number of funds in each portfolio at the beginning and the end of the sample is also reported. We omit three objective-grouped portfolios with limited numbers of time-series observations. Thus, we are left with eight objective-grouped portfolios and nine stylegrouped portfolios. The objective-grouped portfolios that we retain are numbered 1-8 in Table 1.

The summary statistics in panel B for the equity funds grouped by style are of interest in view of the controversy over the performance of value versus growth strategies. A number of studies claim that value strategies, formed by grouping stocks into hypothetical portfolios with high ratios of book/market value or earnings/price per share, outperform growth strategies [e.g. Basu (1977), Fama and French (1992), Lakonishok, Shleifer and Vishny (1994)]. However, the realized returns on value versus growth-style mutual funds are not so dramatically different. Indeed, among the large-capitalization equity funds, the growth-style fund average return for $1976-94$ was $1.19 \%$ per month, while the value-style fund average was $1.12 \%$.

The mutual fund data do not show significantly higher returns for funds that are classified as value investors. There are two potential differences between the funds and hypothetical portfolios: transactions costs and portfolio composition. Thus, one conjecture is that value funds have not delivered higher returns because they have higher expenses than growth funds. We cannot fully address this transactions cost hypothesis without better data on trading costs, but we do have information on expense ratios. Among the large-capitalization funds in our sample, the growth-style funds have the highest average expense ratios -- just the opposite of what we would expect under the transactions costs hypothesis. This suggests that the fund portfolios differ in composition from the 
hypothetical portfolios used in much of the literature on the book-to-market effect.

\subsection{Style-matched Portfolios}

To further explore the issue of portfolio composition, we construct nine portfolios which feature the same style characteristics as the Morningstar equity style classification. We use these as alternative benchmarks to test our models, and also to further interpret the summary statistics of the funds. The classifications are based on the sum of the price/earnings ratio and market/book ratio (the PEMB "value" index) and on market capitalization.

Portfolios are formed using all firms listed in 1994 on CRSP and Compustat (including the Research tape) as of the end of April for each sample year from 1978 to 1994. Firms are ranked based on their respective PEMB index values and on market capitalization using price and share information at the end of April and book value and earnings information from the previous fiscal year's annual report. Firms with negative book values are excluded. Firms are required to have at least two years of data on Compustat before they are eligible for inclusion in the portfolios. This screen is to minimize the selection bias that occurs from Compustat backfilling data, as discussed by Kothari, Shanken and Sloan (1995) and Fama and French (1993). Firms are split annual into three groups on the basis of their PEMB index value, where the break points are set each year at the 33.3 and 66.7 percentiles of the PEMB index values for the NYSE firms in the sample. Only the NYSE firms are used to calculate the cut-off points in order to better mirror the Morningstar break points. A similar grouping is done based on the market capitalization of the firms, where the break points are set each year as the 33.3 
and 66.7 percentiles of market capitalization for the entire sample of firms. The end result is a $3 \times 3$ classification used to allocate the firms into the nine portfolios. Monthly value-weighted portfolios are formed to correspond to the nine Morningstar fund style classifications.

If a firm delists it is excluded from the portfolio in the delisting month and the proceeds are reinvested in the remaining stocks. Since the last return on the CRSP tapes may or may not be the actual delisting return, there is a potential bias as discussed by Shumway (1997). This could be particularly problematic in the small size and value stocks, which are likely to include many troubled firms which are acquired or go bankrupt. Measurement error in the benchmark returns will lead to inefficiency in our estimation and, if the error is correlated with the residual, will result in bias.

To investigate the magnitude and impact of delisting bias in the monthly benchmark portfolio returns, we recalculate the benchmark returns as suggested by Shumway (1997), using a return of -1 for all performance-related delistings as a conservative check on the sensitivity. We find that the difference between the smallcapitalization, high value portfolio return with versus without Shumway's adjustment is small -- generally much smaller than the NYSE tick size. However, the difference is statistically significantly correlated with the S\&P 500 return and our instrumental variables, which suggest the possibility of a systematic bias. To test the sensitivity of our results to delisting bias, we run some of our tests using both versions of the alternative benchmark returns. The results are summarized below.

Summary statistics of the alternative benchmarks (without the delisting adjustment) are presented in panel C of Table 1, for the May, 1978 through December, 1994 period. 
These may be compared with the statistics in panel B for the actual mutual funds (although the sample periods are different, the statistics for the funds in Panel B are in fact, similar on the shorter subperiod). While the differences in the average returns across the hypothetical "style" portfolios are not statistically different, they do mirror the patterns found in previous research [e.g. Fama and French $(1992,1993)]$. The value portfolios have higher average returns than the growth portfolios, and the difference is the largest for the small-cap groupings. Thus, even when the hypothetical portfolios use a similar definition of value investing, they don't reproduce the patterns of the mutual funds. Note, in particular, that the smaller-cap hypothetical portfolios have higher autocorrelations and standard deviations of return than the mutual funds. This suggests that the hypothetical portfolios contain some smaller and/or more thinly traded stocks than the actual funds.

Previous research is consistent with the view that value-investing mutual funds may hold less extreme portfolios than the hypothetical portfolios in some studies. For example, Loughran (1997) finds that the poor performance of hypothetical portfolios of low bookto-market stocks is concentrated in the smaller, newly-listed issues. Such stocks may not appear frequently in mutual fund portfolios. A comprehensive analysis of the differences between the returns of mutual funds and hypothetical portfolios awaits future research.

\subsection{Market Index and Information Variables}

The most well-known benchmark for measuring performance is the Standard and Poors 500 stock index. The S\&P 500 return, with dividends, is obtained from the Center for Research in Security Prices (CRSP) at the University of Chicago. We also use a set of market-wide variables to condition the analysis. 
The idea in conditional performance evaluation is to account for the fact that there may be public information that is correlated with future market returns. Managers who mechanically use only public information to time the market should get no credit for "superior" ability. By the choice of the instruments $Z_{t}$ we define what is considered to be the public information, and therefore what is "superior."

To represent the public information for our empirical tests we use a collection of variables that previous studies have shown are useful for predicting security returns over time. The variables are: (1) the lagged level of the one-month Treasury bill yield, less its twelve-month lagged moving average (TB), (2) the lagged dividend-to-price ratio for the CRSP value-weighted NYSE and AMEX stock index (DP), (3) a lagged slope of the U.S. Government term structure (TERM), measured as the difference between four-year and one-year fixed-maturity bond yields from the CRSP "FamaBliss" files and (4) a dummy variable indicating that the next month is January (JAN). ${ }^{14}$ Panel D of Table 1 reports summary statistics for the lagged instruments and Panel $\mathrm{E}$ is their sample correlation matrix.

We regress the objective-grouped equity fund portfolio returns over time on a constant and the lagged instruments and find that the instruments are significant. Four of the eleven coefficients on TB have t-ratios below -1.65 and eight of the eleven coefficients on DP are above +2.0. Significant t-ratios are found more frequently in the style-grouped

14 Studies which document predictability using similar variables include Fama and Schwert (1977), Campbell (1987), Breen, Glosten and Jagannathan (1989) and Ferson (1989) for short term interest rates; Fama and French $(1988,1989)$ and Campbell and Shiller (1988) for dividend yields; and Keim and Stambaugh (1986), Campbell (1987) and Fama (1990) for term spreads. Pesaran and Timmerman (1995) document the economic and statistical significance of these variables for the period after 1970. 
portfolios. The regression R-squares for the fund groups are typically somewhat higher than is the R-square for the regression of the Standard and Poors 500 index on the same instruments. This suggests that the funds are responding to the public information variables, which motivates the use of the conditioning information in the performance evaluation.

\section{Empirical Results}

\subsection{Preliminaries}

To set the stage we first estimate a special case of the model. If we let the only instrument in $Z_{t}$ be the constant and set $R^{2}=0$, we obtain an unconditional version of the market timing model:

$$
\text { where } \quad \begin{aligned}
\mathrm{r}_{\mathrm{pt}+1}=a_{\mathrm{p}}+\mathrm{b}_{\mathrm{p}} \mathrm{r}_{\mathrm{mt}+1}+\Lambda_{\mathrm{p}} \mathrm{r}_{\mathrm{mt}+1}{ }^{2}+\mathrm{w}_{\mathrm{t}+1}, \\
\mathrm{~b}_{\mathrm{p}}=\mathrm{h}+\mu_{\mathrm{m}} /\left\{\gamma \sigma_{\mathrm{m}}^{2}\right\}, \\
\Lambda_{\mathrm{p}}=\mathrm{K}^{2} /\left\{\gamma \sigma_{\mathrm{m}}^{2}\right\} .
\end{aligned}
$$

Treynor and Mazuy (1966) first proposed the unconditional market timing regression (10), where $b_{p}$ and $\Lambda_{p}$ are free parameters. They argued that $\Lambda_{p}>0$ indicates market timing ability. The regression is estimated for mutual funds by Grinblatt and Titman (1988), Cumby and Glen (1990) and Ferson and Schadt (1996), who find a tendency for negative estimates of $\Lambda_{\mathrm{p}}$.

Table 2 reports estimates of the unconditional model of (10) for the grouped equity mutual funds. The model is estimated using the GMM, as a special case of the 
system (9). ${ }^{15}$ Each of the seventeen point estimates of the risk aversion parameter, $\gamma$, are negative, seemingly inconsistent with risk aversion on the part of fund managers. The magnitudes are small, but all except one have absolute t-ratios larger than 2.0. The market timing parameters, $\mathrm{K}$, are small but indicate significant timing ability for all but one group. Combined with the negative estimates of $\gamma$, these results are consistent with negative values of $\Lambda_{p}$ in (10). We also use a simple regression approach to the unconditional model, estimating the first line of (10) with the parameters unrestricted. All of the point estimates of $A_{\mathrm{P}}$ are negative and 13 of the 17 have t-ratios below -2.0.

Previous studies find similar evidence of anomalous "negative" market timing ability in unconditional models. Obviously, this makes no economic sense. If funds could really time the market but got the sign wrong, astute investors could profit by taking opposite positions. Note that all of the point estimates of $a_{p}$ are positive in Table 2 with five significant at conventional levels, indicating abnormal performance relative to the model. The point estimates of $h$ are huge positive numbers, which again makes little economic sense. In summary, anomalous results for unconditional market timing models, similar to those observed by previous authors, are also observed here. The results provide

15 The system of moment conditions is:

$$
\begin{aligned}
& \mathrm{u} 1_{\mathrm{t}+1}=\mathrm{r}_{\mathrm{mt}+1}-\mu_{\mathrm{m}} \\
& \mathrm{u} 2_{\mathrm{t}+1}=\sigma_{\mathrm{m}}{ }^{2}-\left(\mathrm{r}_{\mathrm{mt}+1}-\mu_{\mathrm{m}}\right)^{2} \\
& \mathrm{u} 3_{\mathrm{t}+1}=\left[\mathrm{r}_{\mathrm{pt}+1}-\mathrm{a}_{\mathrm{p}}-\left(\mathrm{h}+\mu_{\mathrm{m}} / / \sigma_{\mathrm{m}}{ }^{2}\right) \mathrm{r}_{\mathrm{mt}+1}-\left(\mathrm{K}^{2} / / \sigma_{\mathrm{m}}{ }^{2}\right) \mathrm{r}_{\mathrm{mt}+1}{ }^{2}\right]\left(1, \mathrm{r}_{\mathrm{mt}+1}, \mathrm{r}_{\mathrm{mt}+1}{ }^{2}\right) \\
& \mathrm{u} 4_{\mathrm{t}+1}=\mathrm{u} 3_{\mathrm{t}+1}{ }^{2}-\left(\sigma_{\mathrm{m}}{ }^{2}+\mu_{\mathrm{m}}{ }^{2}\right)\left(\mathrm{K}^{2} / \gamma^{2} \sigma_{\mathrm{m}}{ }^{2}\right),
\end{aligned}
$$

where the fourth moment condition follows from the definition of $w_{1+1}$ as a special case of equation (7). The model implies $E\left\{u 1_{t+1}, u 2_{t+1}, u 3_{t+1}, u 4_{t+1}\right\}=0$. With a single fund excess return, there are six parameters and six moment conditions. 
convincing evidence that the unconditional model is poorly specified, which further motivates the examination of our conditional market timing model.

\subsection{Results for Equity Fund Groups}

Table 3 reports estimates for the conditional market timing model. The system (9) is estimated separately for each of the equally-weighted portfolios of U.S. equity funds and the benchmark portfolio is taken to be the S\&P500. ${ }^{16}$ The estimates of the parameters for the expected market return are not shown to save space. These are similar across the equations, even though the estimation allows them to differ without constraint. The magnitudes of the market-wide parameters are also consistent with economic intuition. For example, the coefficient on TB is negative and significant. The estimates of $\sigma_{\mathrm{m}}{ }^{2}$, as shown in the table, are close to the sample variance of the S\&P500 and the $R^{2}$ is between $3.7 \%$ and $5.1 \%$. Thus, the market-wide parameter estimates suggest that conditioning on the lagged variables is relevant.

In the conditional market timing model of Table 3 , the estimates of the quality of the market timing signals, as given by $\mathrm{K}$ or $\rho^{2}$, are small and not significantly different from zero. Thus, once we control for the public information, the data present no evidence that these funds have any additional market timing information. However, the standard errors of $\rho^{2}$ are large, so the power of the tests may be relatively low.

The estimates of the $\alpha_{\mathrm{p}}$ in Table 3 are numerically small and statistically insignificant (with one exception: The technology funds' t-statistic is 2.64 ), providing little

16 We experimented with models combining several funds in a simultaneous system, but were unable to stack more than 2 or 3 fund equations without encountering singularities in either the gradient matrix or the weighting matrix. 
evidence of "abnormal" returns relative to the model. This is in contrast with the unconditional models in Table 2, where five of the seventeen fund groups generated significant positive alphas. Significant positive alphas and negative timing coefficients are interpreted as evidence of model misspecification by Grant (1977), Jagannathan and Korajczyk (1986) and Coggin, et.al (1993). Thus, the conditional version of the market timing model appears to be a better specification.

The evidence of insignificant timing ability and small alphas in a conditional market timing model for equity funds confirms the conclusions of Ferson and Schadt (1996), who studied 68 equity funds for the $1968-90$ period. Our refined model produces some additional insights. For example, in Table 3, all of the point estimates of the benchmark preference parameter, h, are positive and strongly statistically significant, suggesting the importance of benchmark investing by mutual funds. The estimates are all between 0.68 and 1.00 , implying benchmark policy weights in an economically reasonable range.

The estimates of the risk aversion parameter $\gamma$ are also interesting. All except two of the objective groups produce positive point estimates in Table 3. While the large standard errors make inferences about the magnitudes imprecise, the values are generally numerically large. The large point estimates are consistent with the view that benchmarkinvesting managers have highly concave utility functions around their benchmarks, relative to the conventional standards for consumer risk aversion. In other words, fund managers may be highly risk averse about the "tracking error" of their portfolios.

We ran the model of Table 3 with the restriction that $h=0$. When $h=0$ the risk aversion estimates are much smaller. However, when $\mathrm{h}=0$ the right-tail p-values of the $\mathrm{J}$ - 
tests are smaller in most cases, implying that the estimation procedure "wants" $h$ to be nonzero.

Despite this encouraging evidence for the conditional market timing model with benchmark investors, Hansen's J-test provides some evidence against the model in Table 3. Eight of the 17 fund groups produce goodness-of-fit statistics with p-values less than 0.05. The statistical rejections indicate some misspecification of the model, when applied at the level of fund groups.

As the model is developed for an hypothetical individual fund manager, the potential for aggregation bias arises when using an equally-weighted portfolio of funds. This problem can be analyzed by taking an equally-weighted average of equation (7), where the subscript $i$ denotes an individual. The estimate of $\mathrm{h}$ for a group should be interpreted as the equally-weighted average of the individual benchmark preference parameters. Under the null hypothesis that there is no timing ability $\left(\mathrm{K}_{\mathrm{i}}=0\right.$ for all $\left.i\right)$, the parameter $\gamma$ is the harmonic mean of the individual risk aversions. Under the alternative hypothesis that $\mathrm{K}_{\mathrm{i}}$ is not zero, then provided that there is no correlation across managers between $\mathrm{K}_{\mathrm{i}}{ }^{2}$ and ${V_{\mathrm{i}}}^{-1}$, the parameter $\gamma$ is the harmonic mean of the individual risk aversions and $\mathrm{K}^{2}$ is the equally-weighted average of the $\mathrm{K}_{\mathrm{i}}{ }^{2}$, s. If the correlation between $\mathrm{K}_{\mathrm{i}}{ }^{2}$ and ${\gamma_{i}}^{-1}$ is not zero, the aggregate model will garble together signal quality and risk aversion. ${ }^{17}$

17 We estimate the sample correlation between the estimates of $K_{i}$ and $\gamma_{i}$ for the individual asset allocator funds obtaining a value of only -0.14 . Moving outside the model, there are other reasons that risk aversion and signal quality may be hard to unscramble. For example, Huberman and Kandel (1993) present a model in which managers with more precise forecasts of the market signal their precision by exaggerating the response to their signals. Such managers would appear to be less risk averse. 
As we suggested earlier, the finding that mutual funds have no better than public information at the group level may reflect a lack of power. Clearly, at a high enough level of aggregation funds can't time the market, since in the aggregate they approximately are the market. The sample of U.S. equity funds may also not contain many funds that attempt to aggressively time the market. The results for the asset allocator funds may therefore provide additional insights.

\subsection{Results for Asset Allocator Funds}

Tables 4 and 5 report results for the asset allocator funds. Table 4 reports results at the group level, while Table 5 summarizes results for the individual funds. We delete funds with fewer than 60 monthly observations, leaving 106 funds for analysis. The S\&P 500 serves as the benchmark. We apply Hansen's J-test to the models for the individual funds, and find that for about $70 \%$ of the funds we do not reject the model at the $5 \%$ level.

In Table 4 the allocator funds are aggregated into two groups: all funds, and those funds whose individual test results produced p-values above 0.05 . The purpose is to see if the parameter values are different depending on whether or not the model is rejected by Hansen's J-test. The point estimates of the market-wide parameters are similar across the two groups and similar to those for the equity funds. The estimates of the risk aversion parameter are again large by conventional standards, and imprecise, but similar for both groups of funds. The estimates of the benchmark preference parameter, $h$, are 0.563 and 0.564 . The values are smaller for the asset allocator funds than for the equity funds. This seems sensible, as a market timing fund is likely to have a smaller policy 
weight on equity than a straight equity fund. The $\mathrm{h}$ parameters are strongly significant, with t-ratios above 8.0, confirming the impression that benchmark investing is relevant.

There is no evidence of abnormal performance or timing ability in Table 4. The $\rho^{2}$ coefficients measuring the market timing ability are not significantly different from zero, and the alphas are small. In summary, the overall results are similar for the group of funds for which the J-test rejects the model and for those funds where the model is not rejected. This increases our confidence in drawing economic conclusions from a model that can be rejected by the data. ${ }^{18}$

Table 5 summarizes the cross-sectional distributions of the parameter estimates for the individual asset allocator funds. Panel A focusses on the t-ratios and panel B summarizes the point estimates of the coefficients. The market-wide parameter estimates complement the previous results. The coefficients are tightly and nearly symmetrically distributed about values close to those produced by the group averages. For example, $80 \%$ of the coefficients on the Treasury bill are between -.29 and -.88 . Thus, there is little evidence that aggregation bias from combining the individual equations distorts the market-wide parameter estimates.

The distributions of the fund-specific parameters in Table 5 also generally support the group results. The t-ratios of the benchmark preference parameter, $h$, are concentrated above 2.3. The t-ratios for the parameters $\gamma, \alpha_{\mathrm{p}}$ and $\rho^{2}$ are concentrated near zero. The alpha coefficients are approximately symmetrically distributed near zero, with only a couple large values (the maximum alpha is just significant at the $5 \%$ level,

18 We have also estimated the model on groups of asset allocator funds, formed according to equity investment style and fixed income style, as reported by Morningstar. The results for these groups are similar. 
based on a Bonferroni test). The distribution of the $\rho^{2}$ coefficient is tightly concentrated near zero but with a few large values, also consistent with the group results. The upper quartile of the $\rho^{2}$ values is less than 0.0001 , but the upper $10 \%$ are above 0.80 . These few large point estimates of $\rho^{2}$ are the only exception to the finding of no abnormal performance or market timing ability in the conditional model.

The estimates of the benchmark preference parameter, $h$, have an interquartile range of 0.52 to 0.89 . These economically reasonable magnitudes increase our confidence that the idea of benchmark investing is relevant for market-timing mutual funds. The estimates of the risk aversion parameter, $\gamma$, present a skewed distribution. The mean is much larger, at 93.6, than the median of -13.4. The estimates are again imprecise. Only one of the 106 funds produces an individually "significant" negative estimate of $v$ (t-ratio below -1.645), and none of the extreme values are significant by the Bonferroni test.

Panel $\mathrm{C}$ of Table 5 presents a cross-sectional correlation matrix of the coefficient estimates for the 106 funds. The highest correlations are between the market-wide parameters of the model, such as the regression coefficients on the dividend yield and the term spread. Otherwise the correlations are small. ${ }^{19}$ Previous studies have found a strong negative cross-sectional relation between estimates of timing information and alpha in unconditional models [e.g. Jagannathan and Korajczyk (1986)], which they interpret as evidence of model misspecification. In the conditional model, the correlation between $\rho^{2}$ and $\alpha$ is only -.06 , the correlation between $\alpha_{\mathrm{p}}$ and $\gamma$ is -0.16 and the correlation between $\rho^{2}$ and $V$ is 0.16 . These results reinforce our previous impression that the conditional

${ }^{19}$ However, for a given fund the correlation between the coefficient estimates for $h$ and $\gamma$ can be fairly high. We estimate correlations between .76 and .96 for the models in Tables 3 and 4. 
model is a better specification.

\subsection{Analysis of Portfolio Holdings}

Our model parameters should describe the portfolio weights of mutua! funds. The parameters are estimated using only rate of return data, so we can check the validity of the results by examining the actual portfolio weights. We collected end-of-quarter data on the holdings of the asset allocator funds for ten quarters, as shown in panels $F$ and $G$ of Table 1. We use the portfolio weights in U.S. equities to conduct a number of additional tests, which are summarized in this section. ${ }^{20}$

\subsubsection{The Cross-section of Equity Weights}

The comparative statics of our model are given by the derivatives of equation (5), using equation (3) to define the conditional moments. The model implies that the expected value of the portfolio weight in stock should be an increasing function of the parameters $\mathrm{h}, \mathrm{K}^{2}$ and $\gamma^{-1}$. The time-series standard deviation of the weight in stock should be increasing in $\mathrm{K}^{2}$ and $\gamma^{-1}$, and unrelated to $\mathrm{h}$.

Table 6 reports multiple regressions, taken across the 102 asset allocator funds with at least two quarters of data on their weights. The time-series means of the weights in stock and the standard deviations of the weights are regressed cross-sectionally, on the estimates of the parameters $\mathrm{h}, \mathrm{r}^{-1}$ and $\mathrm{K}^{2}$. T-ratios from the multiple regressions are in parentheses. Results for the average weights are reported in the first row of the table.

20 Morningstar did not distinguish foreign from U.S. equity holdings in the first two quarters of our sample. The findings of this section, however, are robust to excluding funds with more than $20 \%$ in foreign equities in any one quarter. 
The coefficients on $h, \gamma^{-1}$ and $\mathrm{K}^{2}$ are positive, as predicted by the model, but the coefficient on $\mathrm{K}^{2}$ is not statistically significant. Thus, funds whose return patterns imply larger estimates for their risk tolerance and benchmark policy weights on equity, actually hold more equity on average. Market timing does not show up as a significant factor.

Regressions for the standard deviation of the weights are shown on the second line of Table 6. The coefficients on $\mathrm{K}^{2}$ and $\gamma^{-1}$ are positive, as predicted by the model, but the coefficient on $\gamma^{-1}$ is not statistically significant. Finally, the coefficient on $\mathrm{h}$ is insignificant in the regression for the standard deviation, where the model predicts no relation. Overall, the results in Table 6 are favorable to the validity of the model.

\subsubsection{Market Timing and the Portfolio Weights}

One response to our concern that the lack of evidence of timing ability may reflect low power is to use the portfolio holdings data to take a different tack on the general question: Is there information in the fund portfolio weights about the future market return, and is that information essentially captured by the lagged instruments? To address this question, we use the portfolio weights in a manner similar to Harvey and Graham (1996), who studied the recommended holdings of investment newsletters.

If managers are able to time the market, we would expect a positive correlation between the change in a fund's stock holdings and the subsequent market return. We run time-series regressions of the future S\&P 500 excess return on the changes in the equity holdings of the individual funds, and also a pooled, time-series and cross-section regression. Panel $\mathrm{A}$ of Table 7 provides the results for 1-month, 2-month and 3-month future market returns. The results for the pooled regression show significant negative 
coefficients on the change in stock holdings, consistent with the previously documented "negative" market timing results in unconditional models.

We run the regressions on the weight changes, including the public information variables as additional regressors, shown in panel B of Table 7. A positive coefficient on the change in the holdings implies an ability to time market movements conditional on the public information. The pooled regression produces a negative coefficient on the change in the equity holdings for 1-month ahead market returns, positive coefficients for 2-month and 3-month returns, and none are significantly different from zero. These results are consistent with an inability of fund managers to time market movements, once we control for the public information variables.

In summary, the results of Table 7 support those obtained using our model on returns data. The unconditional analysis appears to detect timing ability, but of the "wrong" sign. Conditioning on the public information removes the negative market timing, and there is no significant evidence of additional timing information.

\subsection{Tests Using Altemative Benchmarks}

The rejections of the conditional market timing model could indicate a problem with using the S\&P 500 as a benchmark, as some funds may use benchmarks that differ importantly from the S\&P 500. This section describes the results for models using the alternative benchmarks described in section 4.2. The sample period is May of 1978 through December of 1994, so there are 28 fewer observations than in the previous tables. We estimate the models for the equity funds grouped by investment style and for the allocator funds, also grouped by style (tables are available by request). 
The results generally confirm our previous findings based on the S\&P 500. The estimates suggest that the funds behave as benchmark investors, as most of the estimates of the $h$ parameter have large t-ratios. The point estimates of $h$ are between 0.46 and 0.68 for the allocator fund groups, and range as high as 1.00 for the equity funds. There is not much evidence that the funds have significant conditional timing ability. The values of $\rho^{2}$ are generally small and insignificant, but there are two cases where the $\rho^{2}$ values are larger than 0.33 ; these occurring in the asset allocator funds.

Most of the estimates of alpha are numerically small and insignificant, but three of the 14 groups' $\alpha_{\mathrm{p}}$ t-ratios are larger than 2.0 in absolute value. One is negative and two are positive. The absolute magnitudes of the estimates of $\gamma$ are large by conventional standards, as we observed before. We find negative point estimates of $\gamma$ more frequently than before -- six of the 14 cases produce negative values, but none are significant. Finally, Hansen's J-test rejects the model, with five of the 14 cases producing p-values below 0.05 . Overall, the tests show that the main results are robust to the use of the alternative benchmarks in place of the S\&P 500.

We estimated the unconditional model of Table 2, replacing the S\&P 500 with the alternative benchmark matching the style category of the fund. We find that the results are similar to those reported in Table 2. We ran these tests using the two versions of the style-based benchmarks -- one with the delisting-bias adjustment and one without the adjustment. The results with or without the adjustment were very similar, indicating that the delisting bias in the alternative benchmarks does not materially affect the findings. 


\subsection{The Effects of Selectivity}

As funds are likely to engage in security selection, we would like to assess its impact on the results of the market-timing model. In the presence of selectivity we can model the portfolio weight vector held by a fund, $w_{p}$ (where $1-\Sigma_{i} w_{i p}$ represents cash holdings) as the sum of two parts: $w_{p}=w_{T}+w_{s}$, where $w_{s}$ reflects the fund's selectivity decisions. Assume that $\mathrm{w}_{\mathrm{T}}=\mathrm{x}_{\mathrm{m}}$, where $\mathrm{w}_{\mathrm{m}}$ is the weight defining the "market" portfolio as $r_{m}=w_{m}$ ' $r$, and $x$ is the timing decision, given by equation (5) of our model. The excess return of the fund is $w_{p}{ }^{\prime} r=x r_{m}+w_{s}$ 'r, where $r$ is the vector of the risky assets' excess returns. If this is the "true". model, it follows by substitution that the error term in equation (7) is given by the expression:

$$
v_{t+1}=w_{s}{ }^{\prime} r_{t+1}+Q_{1} r_{m, t+1} \epsilon_{t+1}
$$

Equation (11) provides the basis for a specification analysis in the presence of selectivity.

Our tests and estimates of the parameters are based on the moment conditions

from system (9): $E\left\{v_{t+1}\left[1, Z_{t}, r_{m, t+1}, r_{m}{ }^{2}+1\right]\right\}=0$, where we separate the constant term from the nonconstant lagged instruments, $Z_{t}$. If there is no selectivity, $w_{s}{ }^{\prime} r_{t+1}=0$ and these moment conditions should hold. It is useful to consider the effects of selectivity, concentrating on the three conditions: $(a), E\left(v_{t+1}\right)=0 ;(b), E\left(v_{t+1} Z_{t}\right)=0$ and (c), $\mathrm{E}\left\{\mathrm{v}_{\mathrm{t}+1}\left[\mathrm{r}_{\mathrm{m}, \mathrm{t}+1}, \mathrm{r}_{\mathrm{m}{ }_{\mathrm{t}+1}}^{2}\right]\right\}=0$.

Under selectivity condition (a) will fail, as equation (11) implies that $E\left(v_{t+1}\right)=E\left(w_{s}{ }^{\prime} r_{t+1}\right)$ is the expected selectivity return. This is the motivation for including the intercept, $\alpha_{\mathrm{p}}$, in the empirical model. Including a constant alpha ensures that the 
error term in the model will average zero in the sample. Thus a failure of condition (a) will not lead to a rejection of the model.

Since the error term $v_{t+1}$ will have mean equal to zero, condition (b) may be interpreted as: $E\left(v_{t+1} Z_{t}\right)=\operatorname{Cov}\left(w_{s}{ }^{\prime} r_{t+1}, Z_{t}\right)=0$. This condition will hold only if the return to selectivity is uncorrelated with the lagged instruments. As the selectivity return is likely to be correlated with public information, the failure of condition (b) could lead to rejections of the model and biases in the parameter estimates.

We can address the sensitivity of the results to the failure of condition (b) by modifying the model in such a way as to guarantee that condition (b) will hold. This is done by replacing the constant intercept with a time-varying function of the lagged instruments: $\alpha_{0}+\alpha_{1} \mathrm{Z}_{\mathrm{t}}$. Including this time-varying intercept ensures that the sample mean of $v_{t+1} Z_{t}$ is zero in the altered model. Unfortunately, with the new parameters $\alpha_{1}$ the model is underidentified. However, if we set $\mathrm{K}=0$-- consistent with our empirical findings on the full model -- the model is exactly identified and can be estimated (the number of moment conditions equals number of parameters, and Hansen's J-statistic does not apply).

We revisit the models of Table 3, using the linear specification for alpha and setting $K=0$. We find that the market-wide parameter values are similar to the original model. We also find highly significant benchmark preference parameters and estimates that suggest funds are highly risk averse benchmark investors. The values of $h$ range between 0.79 and 0.98 and all are highly significant ( $t$-ratios larger than 6.8 ). The estimates of the risk aversion parameter, $v$, range between 38 and 254, with four t-ratios larger than 2.0 and eight larger than 1.65. Thus, our main results seem robust to 
correlation between selectivity returns and the lagged instruments.

We now turn to the last condition, (c): $E\left\{v_{t+1}\left[r_{m, t+1}, r_{m}^{2} t+1\right]\right\}=0$. This condition can fail if the selectivity return is correlated with the market return, $r_{m}$, or its square. As timing and selectivity are known to be difficult to separate empirically, this is a plausible scenario. To investigate the sensitivity of our results, we change the instruments to include only the lagged instruments in the equation for $u 5_{p, t+1}$ in the system (9). The modified model therefore uses only the restriction that the error is mean zero given the lagged instruments, as is common in the asset pricing literature using the GMM. Running this model on the grouped equity funds, the estimates of the benchmark preference parameter, $h$, are generally less precise than before, but the magnitudes are similar. Four of the 17 t-ratios are larger than 2.0 and three more are marginally significant at the $10 \%$ level. The estimates of the risk aversion parameter are all positive, and sixteen of the 17 are in the range $(7.6,54)$. Thus, the point estimates continue to indicate that mutual funds behave as risk averse, benchmark investors.

The J-test for the overidentifying restrictions no longer rejects the model when condition (c) is not imposed. This could indicate that the failure of condition (c) is an important source of the model rejections, or it could reflect a test with low power. In either case, our main conclusions about the significance of benchmark investing and our finding of high values of risk aversion for returns relative to the benchmark, remain intact. When we selectively relax the moment conditions that are sensitive to stock picking behavior, we find that our main conclusions still hold. 


\subsection{Robustness of the Results}

We conduct a number of additional experiments in which we estimate the model with various changes in the instrumental variables, moment conditions, and restrictions on the model parameters. The purpose of these experiments is to further assess the robustness of the results to variations in the model and the tests.

We ran a version of the model using only lagged instruments, but including an additional instrument designed to capture fund "momentum." This instrument is the previous six month lagged return for the fund, resulting in a loss of the first six months of data. The results are similar to those reported above, except that we find generally larger t-statistics for the $h$ parameter.

We estimated a version of the model where we constrained $\mathrm{K}$ to equal zero, using only lagged instruments and the fund groups from Table 3 . We found all of the point estimates of $\gamma$ were positive and between the values of 13 and 57. All of the point estimates of $\mathrm{h}$ were between 0.63 and 1.10, and five had t-ratios larger than 2.0. None of the J-tests rejected the model. The results are therefore similar to what we find when $\mathrm{K}$ is a free parameter.

We estimate the model using only lagged instruments for the individual allocator funds and examine the cross-sectional distributions of the results, as in Table 5. The distributions of the market-wide parameters are generally consistent with the previous results. The tests provide little evidence of significant abnormal performance or market timing ability.

In a final experiment, we modify the moment conditions of the system (9) to incorporate an additional restriction on the error term of the equation (7). If the model 
captures a fund's portfolio weight in the benchmark index with no error, the residual $v_{t+1}$ of (7) satisfies the condition $\mathrm{E}\left(\mathrm{v}_{\mathrm{t}+1}{ }^{2}\right)=\mathrm{Q}_{1}{ }^{2}\left(\sigma_{\mathrm{m}}{ }^{2}+\mu_{\mathrm{m}}{ }^{2}\right)$. The analog of this restriction is used in the unconditional timing model of Table 2 in order to identify the full set of parameters; a similar restriction is used in a two step approach by Coggin, et al. (1993). We impose this additional restriction on our conditional market timing model by including an additional moment condition:

$$
\mathrm{u} 6_{\mathrm{pt}+1}=\mathrm{u} 5_{\mathrm{pt}+1}^{2}-\mathrm{Q}_{1}^{2}\left({\sigma_{\mathrm{m}}}^{2}+\mu_{\mathrm{m}}{ }^{2}\right) \text {, with } \mathrm{E}\left(\mathrm{u} 6_{\mathrm{pt}+1}\right)=0 \text {. }
$$

When applied to the equity funds grouped by style, this model produces similar parameter values to those in Table 3. The main difference is that the J-test does not reject the model and the standard errors of the coefficients are larger.

In summary, this section establishes that our main results are robust to severa] variations in the model specification. These additional experiments further support our conclusions about the significance of benchmark investing. We find significant benchmark investing parameters, high values of risk aversion for returns relative to the benchmark, and no evidence -- once we control for public information -- that mutual funds have significant market timing abilities.

\section{Concluding Remarks}

This paper studies the market timing ability of mutual funds using models that: (1) allow the utility function to depend on returns in excess of a benchmark; (2) distinguish timing based on lagged, publicly available information variables from timing based on superior information; and (3) simultaneously estimate risk aversion for tracking error and the precision of the market timing signal. We use a sample of more than 400 U.S. mutual 
funds for 1976-94, including a subsample with explicit asset allocation objectives.

In our conditional market timing models the parameter estimates are generally more economically reasonable than in much of the previous literature on market timing. The parameter estimates imply that U.S equity mutual funds behave as highly risk averse, benchmark investors. After controlling for the public information variables we find little evidence that the mutual funds have market timing ability. We corroborate the validity of these findings, which are based on rate of return data, by conducting additional tests on the mutual funds actual equity holdings. Finally, we document that the value-investing equity mutual funds in our sample do not earn higher average returns than growth-style funds, while in hypothetical portfolios of stocks grouped by similar criteria, value portfolios return more than growth portfolios.

The results of this paper suggest a number of interesting avenues for future research. A comprehensive empirical analysis of the difference between mutual fund and hypothetical portfolio returns is clearly called for. In this study we used a collection of four popular instruments to represent the public information, and we found no evidence of timing ability beyond the information in these variables. The unconditional model, using no instruments, found significant "timing" coefficients. By varying the instrument set, it should be possible to conduct an attribution analysis of fund performance. Conditional estimates of total performance (i.e. timing plus selectivity) could be developed by extending conditional timing models using contingent claims methods similar to Connor and Korajczyk (1991) and Glosten and Jagannathan (1994).

Further extensions may improve upon the performance of the models of this paper. A model with multiple asset classes and multiple signals is one natural extension. 
Incorporating timing signals that may be informative about variance is another important extension, in view of Breen, Glosten and Jagannathan (1989) and other studies that find some of the lagged instruments are informative about market volatility. Extending the analysis from the single-period model of this paper to a dynamic intertemporal model may also result in richer predictions about the behavior of market-timing fund managers. Finally, in addition to trading on market timing information, funds may trade in response to exogenous liquidity demands [see Edelen (1996) and Ferson and Warther (1996)]. Such trades may obscure market timing activity. Therefore, it could be useful to incorporate liquidity effects. Much interesting work remains to be done in the area of conditional performance evaluation. 


\section{REFERENCES}

Admati, Anat R. and P. Pfleiderer, 1997, Does it all add up? Benchmarks and the Compensation of Portfolio Managers, Journal of Business 70, 323-350.

Admati, Admati, and Stephen A. Ross, 1985, Measuring investment performance in a rational expectations equilibrium model, Journal of Business 58, 1-26.

Admati, Anat R., S. Bhattacharya, S. Ross and P. Pfleiderer, 1986, On Timing and Selectivity, Journal of Finance 41, 715-30.

Basu, Sanjoy, 1977, The investment performance of common stocks in relation to their price-earnings ratios: A test of the efficient markets hypothesis, Journal of Finance 32, $663-682$.

Black, Fisher, 1972, Capital market equilibrium with restricted borrowing, Journal of Business 45, 444-455.

Breen, Richard, L. Glosten and R. Jagannathan, 1989, Economic significance of predictable variations in stock index returns, Journal of Finance 44, 1177-1190.

Brennan, Michael J., 1993, Agency and asset pricing, IFA working paper 172-93, London Business School.

Brown, Keith C., W.V. Harlow and Laura Starks, 1996, Of tournaments and temptations: An analysis of managerial incentives in the mutual fund industry, Journal of Finance 51, $85-110$.

Brown, Stephen, William Goetzmann, Roger Ibbotson and Stephen Ross, 1992, Survivorship bias in performance studies, Review of Financial Studies 5, 553-580.

Campbell, John Y., 1987, Stock returns and the term structure, Journal of Financial Economics 18, 373-399.

Campbell, John Y. and Robert J. Shiller, 1988, The dividend price ratio and expectations of future dividends and discount factors, Review of Financial Studies 1, 195-228.

Chen, Zhiwu, and Peter J. Knez, 1996, Portfolio performance measurement: Theory and applications, Review of Financial Studies 9, 511-556.

Chevalier, Judith and. Glen Ellison, 1997, Risk taking by mutual funds as a response to incentives, working paper, University of Chicago.

Chiu, Shean-Bii, and V. Vance Roley, 1992, Risk incentives in mutual fund management: Theory and empirical results, working paper, University of Washington.

Coggin, T. Daniel, Frank J. Fabozzi and Shafiqur Rahman, 1993, The investment 
performance of U.S. Equity Pension fund managers, Journal of Finance 48, 1039-1056.

Connor, Gregory and Robert A. Korajczyk, 1991, The attributes, behavior and performance of U.S. mutual funds, Review of Quantitative Finance and Accounting 1, 526.

Cumby, Robert and Jack Glen, 1990, Evaluating the performance of international mutual funds, Journal of Finance 45, 497-521.

Dybvig, Philip H., and Stephen A. Ross, 1985, Differential information and performance measurement using a security market line, Journal of Finance 40, 383-99.

Edelen, Roger, 1996, The relation between mutual fund flow, trading activity and performance, working paper, Wharton School.

Fama, Eugene F., 1990, Stock returns, expected returns and real activity, Journal of Finance 45, 1089-1108.

Fama, Eugene F., and Kenneth R, French 1988, Dividend yields and expected stock returns, Journal of Financial Economics 22, 3-25.

Fama, Eugene F., and Kenneth R. French, 1989, Business conditions and expected stock returns, Journal of Financial Economics 25, 23-50.

Fama, Eugene F., and Kenneth R. French, 1992, The cross-section of expected returns, Journal of Finance 47, 427-465.

Fama, Eugene F., and Kenneth R. French, 1993, Common risk factors in the returns on stocks and bonds, Journal of Financial Economics 33, 5-56.

Fama, Eugene F., G. William Schwert, 1977, Asset returns and inflation, Journal of Financial Economics 5, 115-46.

Ferson, Wayne E, 1989, Changes in expected security returns, risk and the level of interest rates, Journal of Finance 44, 1191-1218.

Ferson, W., and Rudi Schadt, 1996, Measuring fund strategy and performance in changing economic conditions, Journal of Finance 51, 425-462.

Ferson, W., and Vincent A. Warther, 1996, Evaluating fund performance in a dynamic market, Financial Analysts Journal 52, no. 6, pp.20-28.

Glosten, Lawrence, and Ravi Jagannathan, 1994, A contingent claims approach to performance evaluation, Journal of Empirical Finance 1, 133-166.

Golec, J. H:, 1992, Empirical tests of the principal-agent model of the investor-investment advisor relation, Journal of Financial and Quantitative Analysis 27, 91-95. 
Grant, Dwight, 1977, Portfolio performance and the "cost" of timing decisions, Journal of Finance 32, 837-846.

Grinblatt, Mark and Sheridan Titman, 1988, The evaluation of mutual fund performance: an Analysis of monthly returns, working paper, UCLA.

Grinblatt, Mark, Sheridan Titman and Russell Wermers, 1995, Momentum strategies, portfolio performance and herding: A study of mutual fund behavior, American Economic Review 85, 1088-1105.

Grinold, Richard C. and Ronald N. Kahn, 1995, Active portfolio management, Irwin Press, Chicago.

Grossman, Sanford J., and J.E. Stiglitz, 1980, On the impossibility of informationally efficient markets, American Economic Review 70, 393-408.

Hansen, Lars P., 1982, Large sample properties of the generalized method of moments estimators, Econometrica 50, 1029-1054.

Harvey, Campbell, and John Graham, 1996, Market timing ability and volatility implied in investment newsletter' asset allocation recommendations, Journal of Financial Economics $42,397-421$.

Heinkel, Robert, and Neal M. Stoughton, 1995, A new method for portfolio performance measurement, working paper, University of British Columbia.

Huberman, Gur, and Shmuel Kandel, 1993, On the incentives for money managers: A signalling approach, European Economic Review 37, 1065-1081.

Jagannathan, Ravi, and Robert A. Korajczyk, 1986, Assessing the market timing performance of managed portfolios, Journal of Business 59, 217-236.

Jensen, Michael C. 1968, The performance of mutual funds in the period 1945-1964, Journal of Finance 23, 389-46.

Keim, Donald B. and Robert F. Stambaugh, 1986, Predicting returns in the bond and stock markets, Journal of Financial Economics 17, 357-90.

Kothari, S.P., Jay Shanken and Richard G. Sloan, 1995, Another look at the cross-section of expected stock returns, Journal of Finance 50, 186-224.

Loughran, Tim, 1997, Book-to-market across firm size, exchange and seasonality: Is there an effect? Journal of Financial and Quantitative Analysis 32, 249-268.

Kryzanowksi, Lawrence, Simon Lalancette and Minh Chau To, 1996, Performance attribution using an APT with prespecified factors, working paper, Concordia University. 
Lakonishok, Josef, Andrei Shliefer and Rohur W. Vishny, 1994, Contrarian investment, extrapolation, and risk, Journal of Finance 49, 1541-1578.

Malatesta, Paul H., 1992, Professional investors and asset returns, mimeo, University of Washington.

Malkiel, Burton G., 1995, Returns from investing in equity mutual funds 1971-1991, Journal of Finance 50, 549-572.

Maug, Ernst, and Narayan Naik, 1996, Herding and delegated portfolio management: The impact of relative performance evaluation on asset allocation, working paper, London Business School.

Merton, Robert C., and Roy D. Henriksson, 1981, On market timing and investment performance II: Statistical procedures for evaluating forecasting skills, Journal of Business $54,513-534$.

Pesaran, M., and Allan Timmermann, 1995, Predictability of stock returns: Robustness and economic significance, Journal of Finance, 50, 1201-1228.

Rubinstein, Mark, 1973, A comparative statics analysis of risk premiums, Journal of Business 46, 605-615.

Schultz, Ellen E., 1996, "Vanguard bucks trend by cutting fund fees," the Wall Street Journal, January 30, c1-c25.

Sirri, Eric, and Peter Tufano, 1992, Buying and Selling mutual funds: flows, performance, fees and service, working paper, Harvard University.

Sharpe, William. F., 1964, Capital asset prices: A theory of market equilibrium under conditions of risk, Journal of Finance 19, 425-42.

Shumway, Tyler, 1997, The delisting bias in CRSP data, Journal of Finance 52, 327-340.

Starks, Laura, 1987, Performance incentive fees: An agency theoretic approach, Journal of Financial and Quantitative Analysis 22, 17-32.

Stein, C., 1973, Estimating the mean of a multivariate normal distribution, Proceedings of the Prague Symposium on Asymptotic Statistics.

Treynor, Jack, and Kay Mazuy, 1966, Can Mutual funds outguess the market? Harvard Business Review 44, 131-136. 
Table 1

\section{Summary Statistics}

The data are monthly from January, 1976 through December, 1994 (the lagged instruments are known at the end of the previous month). The number of observations is 228 , or fewer for some fund groups. The units are decimal fraction per month. MEAN is the sample mean, STD is the sample standard deviation, NOBS is the number of observations and $\rho_{1}$ is the first order sample autocorrelation. Fund style is determined by Morningstar on the basis of the price/book and earnings/price ratios of the holdings of the funds. The number of funds is recorded at the beginningend of the sample period. The data in panel C are from May, 1978 through December, 1994 (200 observations).

panel A: U.S. Equity Mutual funds grouped by Fund objective

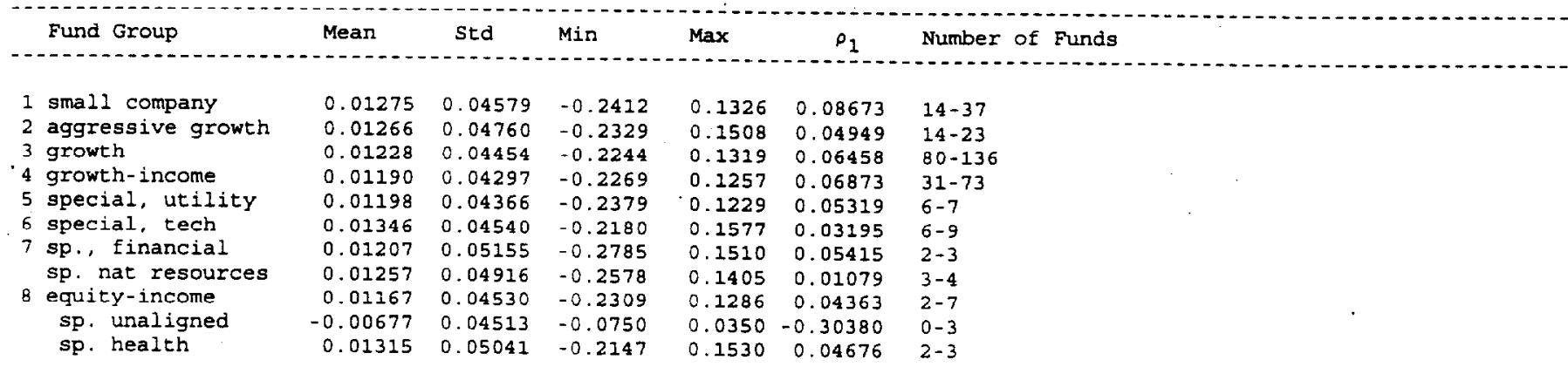

panel B: U. S. Equity Mutual funds grouped by style

\begin{tabular}{|c|c|c|c|c|c|c|c|}
\hline & Fund Group & Mean & Std & Min & $\operatorname{Max}$ & $\rho_{1}$ & Number of Funds \\
\hline 1 & large value & 0.01120 & 0.04172 & -0.2251 & 0.1192 & 0.05416 & $12-30$ \\
\hline 2 & large blend & 0.01160 & 0.04319 & -0.2241 & 0.1285 & 0.06277 & $44-72$ \\
\hline 3 & large growth & 0.01189 & 0.04346 & -0.2046 & 0.1269 & 0.04215 & $10-22$ \\
\hline 4 & medium value & 0.01305 & 0.04438 & -0.2342 & 0.1271 & 0.07690 & $26-32$ \\
\hline 5 & medium blend & 0.01285 & 0.04677 & -0.2343 & 0.1519 & 0.06212 & $15-46$ \\
\hline 6 & medium growth & 0.01270 & 0.04688 & -0.2360 & 0.1383 & 0.05692 & $37-53$ \\
\hline 7 & small value & 0.01300 & 0.04205 & -0.2284 & 0.1146 & 0.06783 & $05-22$ \\
\hline 8 & small blend & 0.01232 & 0.04541 & -0.2192 & 0.1402 & 0.07236 & $12-17$ \\
\hline 9 & small growth & 0.01297 & 0.04793 & -0.2392 & 0.1399 & 0.08072 & $11-25$ \\
\hline
\end{tabular}

panel C: Alternative Equity Benchmarks grouped by Style

$\begin{array}{llllll}\text { Style Group } & \text { Mean } & \text { Std } & \text { Min } & \text { Max } & \\ \text { large value } & 0.01416 & 0.04530 & -0.1830 & 0.1492 & 0.01934 \\ \text { large blend } & 0.01198 & 0.04220 & -0.2037 & 0.1304 & -0.03074 \\ \text { large growth } & 0.01293 & 0.04772 & -0.2310 & 0.1418 & 0.04516 \\ \text { medium value } & 0.01581 & 0.04881 & -0.2682 & 0.1256 & 0.1891 \\ \text { medium blend } & 0.01436 & 0.04904 & -0.2645 & 0.1283 & 0.1430 \\ \text { medium growth } & 0.01271 & 0.06300 & -0.3114 & 0.1531 & 0.1379 \\ \text { small value } & 0.01431 & 0.05158 & -0.2793 & 0.1504 & 0.2669 \\ \text { small blend } & 0.01394 & 0.05416 & -0.2921 & 0.1272 & 0.2300 \\ \text { small growth } & 0.00887 & 0.06806 & -0.3203 & 0.1499 & 0.2191\end{array}$

panel D: The lagged instruments

$\begin{array}{lrllll}\text { instrument } & \text { Mean } & \text { Std } & \text { Min } & \text { Max } & \\ \text { detrended bill rate } & -0.00057 & 0.01494 & -0.05620 & 0.04896 & 0.7813 \\ \text { dividend yield } & 0.04025 & 0.007671 & 0.02702 & 0.06128 & 0.9681 \\ \text { term spread } & 0.00711 & 0.008657 & -0.02600 & 0.02231 & 0.9236 \\ \text { January dummy } & 0.08333 & 0.2770 & 0.000 & 1.000 & -0.0865\end{array}$

panel E: Correlation Matrix of the Instruments

$\begin{array}{lcccc}\text { detrended bill rate } & \text { I } & 0.2422 & -0.5417 & -0.05799 \\ \text { dividend yield } & & 1 & -0.5560 & 0.01231 \\ \text { term spread } & & 1 & -0.008271 \\ \text { January dummy } & & & & 1\end{array}$


Table 1, page 2

panel F: Balanced Funds: Percentage Cash holdings

$\begin{array}{lrrrrr}\text { Quarter } & \text { NOBS } & \ldots . . . \text { Mean } & \text { Std Dev } & \text { Minimum } & \text { Maximum } \\ 92 Q 4 & 43 & 9.7581395 & 11.0473059 & -7.9000000 & 58.2000000 \\ 93 Q 1 & 43 & 7.8488372 & 7.7917347 & -10.3000000 & 27.0000000 \\ 9302 & 44 & 7.1931818 & 7.1302630 & -5.7000000 & 25.1000000 \\ 9303 & 47 & 10.6744681 & 11.6634410 & -3.1000000 & 55.0000000 \\ 9304 & 49 & 9.7163265 & 11.0708955 & -6.1000000 & 58.3000000 \\ 94 Q 1 & 52 & 9.1307692 & 8.7485245 & -2.8000000 & 47.6000000 \\ 94 Q 2 & 56 & 11.0785714 & 11.6021113 & -7.1000000 & 61.3000000 \\ 94 Q 3 & 56 & 11.3732143 & 10.9295844 & -5.1000000 & 62.3000000 \\ 9404 & 62 & 10.7054516 & 11.6079237 & -4.1000000 & 62.1000000 \\ 95 Q 1 & 62 & 9.8709677 & 12.2357630 & -10.6000000 & 61.0000000\end{array}$

panel G: Asset Allocation Funds: Percentage Cash holdings

Quarter NOBS Mean Std Dev Minimum Maximum

$\begin{array}{lllrrr}92 Q 4 & 35 & 13.6085714 & 14.2212635 & 0 & 56.1000000 \\ 93 Q 1 & 37 & 13.3405405 & 12.6511848 & -1.0000000 & 45.0000000 \\ 93 Q 2 & 40 & 12.6300000 & 10.4907334 & -1.0000000 & .43 .7000000 \\ 93 Q 3 & 40 & 12.7300000 & 13.6372454 & 0 & 59.0000000 \\ 93 Q 4 & 41 & 11.1951220 & 14.6544183 & 0 & 56.0000000 \\ 9401 & 42 & 13.0047619 & 15.1532811 & -1.0000000 & 57.0000000 \\ 94 Q 2 & 44 & 18.2340909 & 20.2876975 & 0 & 100.0000000 \\ 94 Q 3 & 44 & 20.8090909 & 24.5258935 & 0.3000000 & 100.0000000 \\ 9404 & 48 & 19.9687500 & 23.4730099 & 0 & 100.0000000 \\ 95 Q 1 & 52 & 17.0403846 & 21.8339927 & -31.0000000 & 100.0000000\end{array}$


Table 2

An Unconditional Market Timing Model

Estimates of the model of equation (10) for one group of funds at a time. The benchmark return is the Standard and Poors 500 index. The data are monthly from 1976.1-1994.12 (the number of observations is 228.) Fund style is determined by Morningstar on the basis of the price/book and earnings/price ratios of the holdings of the funds, crossclassified by the market capitalization relative to the S\&P500. The symbols are as follows: $\sigma_{\mathfrak{m}}{ }^{2}$ is the unconditional variance of the $S \& P 500, \mu_{m}$ is the unconditional mean, $K$ is the parameter which measures the quality of the manager's market timing signal, $V$ is the coefficient of risk aversion, $a_{p}$ is the alpha coefficient for the average abnormal excess return, and $h$ is the benchmark preference parameter. The coefficients are shown on the first line and heteroskedasticity-consistent t-ratios are on the second line.

panel A: Equity Mutual, funds grouped by Investment Style

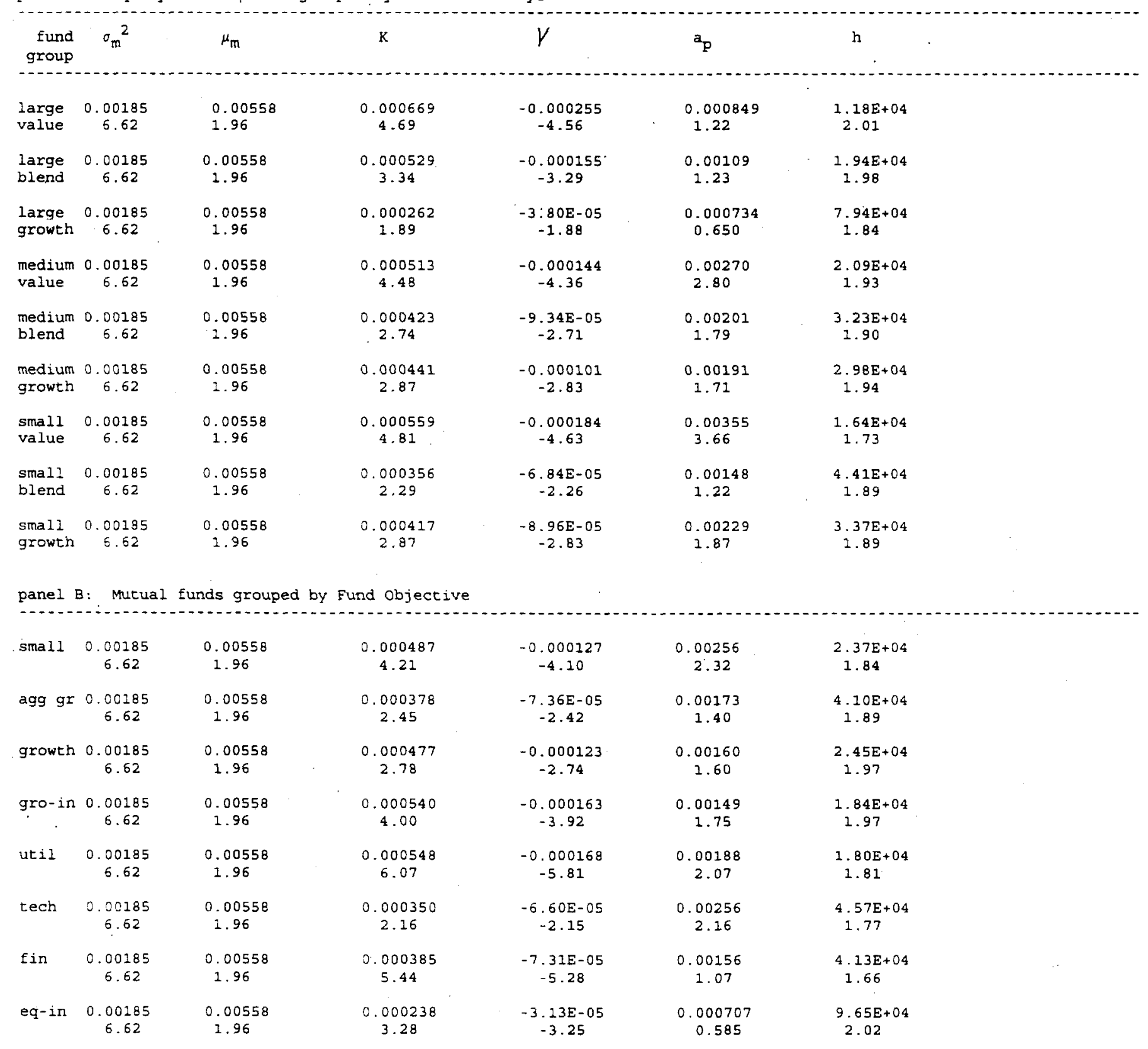


Table 3

\section{A Conditional Market Timing Model: Equity Funds}

Estimates of the system (9) for one group of funds at a time. The benchmark return is the Standard and Poors 500 index. The data are monthly from 1976.1-1994.12 (the lagged instruments are known at the end of the previous month). The number of observations is 228. Fund style is determined by Morningstar on the basis of the price/book and earnings/price ratios of the holdings of the funds, cross-classified by the marke capitalization relative to the S\&P500. The symbols are as follows: $\sigma_{m}{ }^{2}$ is the unconditional variance of the S\&P500, $\mathrm{R}^{2}$ is the coefficient of determination for a regression of the S\&P500 excess return on the lagged instruments, $\gamma$ is the coefficient of risk aversion, $\alpha_{p}$ is the alpha coefficient for the average abnormal excess return, $h$ is the benchmark preference parameter, $\rho^{2}$ is the squared correlation between the manager's market timing signal and the unexpected market return, given the lagged instruments, and chisq is the J-test of the model's overidentifying restrictions. The coefficients are shown on the first line and heteroskedasticity-consistent $t$-ratios are on the second line (in the case of chisq, the right-tail p-value from the Chi-square distribution is on the second line).

Panel A: Mutual funds grouped by Investment Style

\begin{tabular}{|c|c|c|c|c|c|c|c|}
\hline $\begin{array}{l}\text { fund } \\
\text { group }\end{array}$ & $\sigma_{m}^{2}$ & $\mathrm{R}^{2}$ & $\gamma$ & $\alpha_{p}$ & h & $\rho^{2}$ & $\begin{array}{c}\text { chisq } \\
\text { p-value }\end{array}$ \\
\hline $\begin{array}{l}\text { large } \\
\text { value }\end{array}$ & $\begin{array}{r}0.0017 \\
6.580\end{array}$ & $\begin{array}{l}0.047 \\
1.510\end{array}$ & $\begin{array}{l}87.9 \\
0.71\end{array}$ & $\begin{array}{l}-0.0001 \\
-0.0014\end{array}$ & $\begin{array}{l}0.857 \\
12.10\end{array}$ & $\begin{array}{l}0.06 E-2 \\
0.71 E-2\end{array}$ & $\begin{array}{l}6.580 \\
0.087\end{array}$ \\
\hline $\begin{array}{l}\text { large } \\
\text { blend }\end{array}$ & $\begin{array}{r}0.0017 \\
6.547\end{array}$ & $\begin{array}{l}0.043 \\
1.470\end{array}$ & $\begin{array}{l}57.50 \\
0.696\end{array}$ & $\begin{array}{l}0.0002 \\
0.1940\end{array}$ & $\begin{array}{l}0.846 \\
9.010\end{array}$ & $\begin{array}{l}0.49 E-7 \\
0.48 E-6\end{array}$ & $\begin{array}{l}8.490 \\
0.037\end{array}$ \\
\hline $\begin{array}{l}\text { large } \\
\text { growth }\end{array}$ & $\begin{array}{r}0.0018 \\
6.880\end{array}$ & $\begin{array}{l}0.047 \\
1.661\end{array}$ & $\begin{array}{l}42.50 \\
0.901\end{array}$ & $\begin{array}{l}0.0012 \\
0.194\end{array}$ & $\begin{array}{l}0.846 \\
9.010\end{array}$ & $\begin{array}{l}0.66 \mathrm{E}-8 \\
0.18 \mathrm{E}-6\end{array}$ & $\begin{array}{l}16.10 \\
0.001\end{array}$ \\
\hline $\begin{array}{l}\text { medium } \\
\text { value }\end{array}$ & $\begin{array}{r}0.0017 \\
6.321\end{array}$ & $\begin{array}{l}0.042 \\
1.404\end{array}$ & $\begin{array}{l}42.62 \\
0.765\end{array}$ & $\begin{array}{l}0.0015 \\
0.9643\end{array}$ & $\begin{array}{l}0.815 \\
5.886\end{array}$ & $\begin{array}{l}0.01 E-6 \\
0.31 E-7\end{array}$ & $\begin{array}{l}6.851 \\
0.077\end{array}$ \\
\hline $\begin{array}{l}\text { medium } \\
\text { blend }\end{array}$ & $\begin{array}{l}0.0017 \\
6.320\end{array}$ & $\begin{array}{l}0.041 \\
1.440\end{array}$ & $\begin{array}{l}28.00 \\
0.968\end{array}$ & $\begin{array}{l}0.0002 \\
7.9 \mathrm{E}-6\end{array}$ & $\begin{array}{l}0.794 \\
4.940\end{array}$ & $\begin{array}{l}0.06 \mathrm{E}-6 \\
3.95 \mathrm{E}-6\end{array}$ & $\begin{array}{l}7.740 \\
0.052\end{array}$ \\
\hline $\begin{array}{l}\text { medium } \\
\text { growth }\end{array}$ & $\begin{array}{l}0.0017 \\
6.280\end{array}$ & $\begin{array}{l}0.044 \\
1.52\end{array}$ & $\begin{array}{l}35.87 \\
0.822\end{array}$ & $\begin{array}{l}0.0008 \\
0.4846\end{array}$ & $\begin{array}{l}0.849 \\
5.765\end{array}$ & $\begin{array}{l}0.44 \mathrm{E}-3 \\
6.49 \mathrm{E}-3\end{array}$ & $\begin{array}{l}8.853 \\
0.031\end{array}$ \\
\hline $\begin{array}{l}\text { small } \\
\text { value }\end{array}$ & $\begin{array}{r}0.0017 \\
6.45\end{array}$ & $\begin{array}{l}0.044 \\
1.51\end{array}$ & $\begin{array}{l}29.2 \\
0.958\end{array}$ & $\begin{array}{l}0.0016 \\
0.830\end{array}$ & $\begin{array}{l}0.583 \\
4.58\end{array}$ & $\begin{array}{l}0.49 E-9 \\
5.00 E-9\end{array}$ & $\begin{array}{l}7.42 \\
0.060\end{array}$ \\
\hline $\begin{array}{l}\text { small } \\
\text { blend }\end{array}$ & $\begin{array}{r}0.0017 \\
6.48\end{array}$ & $\begin{array}{l}0.049 \\
1.65\end{array}$ & $\begin{array}{l}35.0 \\
0.836\end{array}$ & $\begin{array}{l}0.0005 \\
0.282\end{array}$ & $\begin{array}{l}0.814 \\
5.78\end{array}$ & $\begin{array}{l}0.37 E-7 \\
4.86 E-7\end{array}$ & $\begin{array}{l}11.5 \\
0.010\end{array}$ \\
\hline $\begin{array}{l}\text { small } \\
\text { growth }\end{array}$ & $\begin{array}{r}0.0017 \\
6.43\end{array}$ & $\begin{array}{l}0.045 \\
1.53\end{array}$ & $\begin{array}{l}28.5 \\
0.842\end{array}$ & $\begin{array}{l}0.0009 \\
0.434\end{array}$ & $\begin{array}{l}0.808 \\
4.62\end{array}$ & $\begin{array}{l}0.22 E-7 \\
6.63 E-7\end{array}$ & $\begin{array}{l}8.860 \\
0.03 I\end{array}$ \\
\hline
\end{tabular}

Panel B: Mutual funds grouped by Fund Objective

\begin{tabular}{|c|c|c|c|c|c|c|c|}
\hline $\begin{array}{l}\text { small } \\
\text { company }\end{array}$ & $\begin{array}{c}0.00168 \\
6.36\end{array}$ & $\begin{array}{l}0.039 \\
1.385\end{array}$ & $\begin{array}{l}24.19 \\
0.9953\end{array}$ & $\begin{array}{l}0.001 \\
0.4633\end{array}$ & $\begin{array}{l}0.711 \\
3.811\end{array}$ & $\begin{array}{l}0.45 E-9 \\
5.92 E-8\end{array}$ & $\begin{array}{l}6.475 \\
0.091\end{array}$ \\
\hline agrx. & 0.0017 & 0.051 & 46.88 & 0.0005 & 0.891 & 1. $81 \mathrm{E}-8$ & 10.68 \\
\hline growth & 6.35 & 1.638 & 0.6681 & 0.3493 & 6.588 & $6.89 \mathrm{E}-7$ & 0.0136 \\
\hline growth & $\begin{array}{r}0.0017 \\
6.43\end{array}$ & $\begin{array}{l}0.042 \\
1.472\end{array}$ & $\begin{array}{l}39.84 \\
0.8613\end{array}$ & $\begin{array}{l}0.0006 \\
0.4559\end{array}$ & $\begin{array}{l}0.832 \\
7.008\end{array}$ & $\begin{array}{l}1.37 \mathrm{E}-8 \\
1.85 \mathrm{E}-7\end{array}$ & $\begin{array}{l}9.508 \\
0.0232\end{array}$ \\
\hline growth & 0.0017 & 0.037 & 77.25 & -0.0004 & 0.831 & $8.09 E-5$ & 6.239 \\
\hline income & $6.92 \mathrm{~B}$ & 1.315 & 0.5837 & -0.2708 & 8.292 & 1. $66 \mathrm{E}-3$ & 0.1005 \\
\hline $\begin{array}{l}\text { spec. } \\
\text { utility }\end{array}$ & $\begin{array}{r}0.0017 \\
6.52\end{array}$ & $\begin{array}{l}0.046 \\
1.55\end{array}$ & $\begin{array}{l}41.1 \\
0.753\end{array}$ & $\begin{array}{l}0.0005 \\
0.313\end{array}$ & $\begin{array}{l}0.817 \\
6.47\end{array}$ & $\begin{array}{l}6.81 E-9 \\
2.08 E-7\end{array}$ & $\begin{array}{l}8.69 \\
0.0337\end{array}$ \\
\hline spec. & 0.0019 & 0.044 & $-1 \cdot 1 E+04$ & 0.0027 & 0.990 & $1.60 \mathrm{E}-7$ & 3.05 \\
\hline tech & 7.10 & 1.59 & -0.005 & 2.64 & 12.2 & $1.11 E-6$ & 0.385 \\
\hline $\begin{array}{l}\text { spec. } \\
\text { fin. }\end{array}$ & $\begin{array}{r}0.0016 \\
6.57\end{array}$ & $\begin{array}{l}0.041 \\
1.39\end{array}$ & $\begin{array}{l}41.9 \\
0.505\end{array}$ & $\begin{array}{l}-0.0015 \\
-0.560\end{array}$ & $\begin{array}{l}0.847 \\
3.97\end{array}$ & $\begin{array}{l}0.0489 \\
0.213\end{array}$ & $\begin{array}{l}5.10 \\
0.165\end{array}$ \\
\hline $\begin{array}{l}\text { equity } \\
\text { income }\end{array}$ & $\begin{array}{r}0.0018 \\
6.66\end{array}$ & $\begin{array}{l}0.047 \\
1.52\end{array}$ & $\begin{array}{l}-6397 \\
-0.0059\end{array}$ & $\begin{array}{l}0.0012 \\
0.877\end{array}$ & $\begin{array}{l}0.997 \\
7.48\end{array}$ & $\begin{array}{l}0.950 \\
0.082\end{array}$ & $\begin{array}{l}5.24 \\
0.155\end{array}$ \\
\hline
\end{tabular}


Table 4

A Concitional Market Timing Model: Asset Allocator Funds

Estimates of the system (9) for one group of funds at a time. The benchmark return is the Standard and Poors 500 index. The data are monthly from 1976.1-1994.12 (the lagged instruments are known at the end of the previous month). The number of observations is 228 . Funds are those with objectives as reported by Morningstar being either Balanced or Asset Allocation. The symbols are as follows: $\sigma_{\mathrm{m}}{ }^{2}$ is the unconditional variance of the S\&P500, $\mathrm{R}^{2}$ is the coefficient of determination for a regression of the S\&P500 return on the lagged instruments, $\quad V$ is the coefficient of risk aversion, $\alpha_{\mathrm{p}}$ is the alpha coefficient for the average abnormal excess return, $\mathrm{h}$ is the benchmark preference parameter, and $\rho^{2}$ is the squared correlation between the manager's market timing signal and the market return, given the lagged instruments. Chisq is the J-test of the model's overidentifying restrictions, and p-value is the corresponding right-tail area from the chi-square distribution. The coefficients are shown on the first line and heteroskedasticityconsistent t-ratios are on the second line (in the case of chisq, the right-tail p-value from the Chisquare distribution is on the second line).

\begin{tabular}{|c|c|c|c|c|c|c|c|}
\hline $\begin{array}{l}\text { fund } \\
\text { group }\end{array}$ & $\sigma_{\mathrm{m}}^{2}$ & $\mathrm{R}^{2}$ & V & $\alpha_{\mathrm{p}}$ & $\mathrm{h}$ & $\rho^{2}$ & $\begin{array}{l}\text { chisq } \\
\text { p-value }\end{array}$ \\
\hline all & $\begin{array}{l}0.0019 \\
6.68\end{array}$ & $\begin{array}{l}0.053 \\
1.68\end{array}$ & $\begin{array}{l}95.0 \\
0.762\end{array}$ & $\begin{array}{l}0.0003 \\
0.409\end{array}$ & $\begin{array}{l}0.563 \\
9.26\end{array}$ & $\begin{array}{l}1.79 \mathrm{E}-09 \\
1.96 \mathrm{E}-08\end{array}$ & $\begin{array}{l}16.50 \\
0.0009\end{array}$ \\
\hline $\mathrm{pv}>.05$ & $\begin{array}{l}0.0019 \\
6.69\end{array}$ & $\begin{array}{l}0.053 \\
1.69\end{array}$ & $\begin{array}{l}96.6 \\
0.713\end{array}$ & $\begin{array}{l}0.0005 \\
0.571\end{array}$ & $\begin{array}{l}0.564 \\
8.95\end{array}$ & $\begin{array}{c}1.67 \mathrm{E}-11 \\
1.51 \mathrm{E}-10\end{array}$ & n.a. \\
\hline
\end{tabular}


Table 5

Conditional Market Timing Model: Individual Asset Allocator Funds

The system (9) is estimated for each fund with at least 60 observations, and the cross-sectional results for the 106 funds are shown. The benchmark return is the Standard and Poors 500 index. The data are monthly from 1976.1-1994.12 (the lagged instruments are known at the end of the previous month). The number of observations is between 60 and 228 . Funds are those with objectives as reported by Morningstar as Balanced or Asset Allocation. The symbols are as follows: $\sigma_{\mathrm{m}}{ }^{2}$ is the unconditional variance of the S\&P500, $\left\{\delta_{\mathrm{C}}, \delta_{\mathrm{TB}}, \delta_{\mathrm{DP}}, \delta_{\mathrm{TERM}}, \delta_{\mathrm{JAN}}\right\}$ are the coefficients in the linear regression model for the market excess return on the lagged instruments. $\mathrm{R}^{2}$ is the coefficient of determination for this regression. $V$ is the coefficient of risk aversion, $\alpha p$ is the alpha coefficient for the average abnormal excess return, $\mathrm{h}$ is the benchmark preference parameter, and $\rho^{2}$ is the squared correlation between the manager's market timing signal and the market return, given the lagged instruments. Heteroskedasticity-consistent 1 -statistics are used.

Panel A: Cross-sectional Distribution of t-statistics

\begin{tabular}{|c|c|c|c|c|c|c|c|c|c|c|c|}
\hline & $\sigma_{\mathrm{m}}^{2}$ & $\delta_{\mathrm{C}}$ & $\delta_{\mathrm{TB}}$ & $\delta_{\mathrm{DP}}$ & $\delta_{\text {TERM }}$ & $\delta_{\text {JAN }}$ & $\mathrm{R}^{2}$ & $\gamma$ & $\alpha_{p}$ & $\mathbf{h}$ & $\rho^{2}$ \\
\hline $\min t$ stat & 3.05 & -2.04 & -2.99 & -1.30 & -1.60 & -1.38 & 0.09 & -1.77 & -2.24 & -0.410 & 0.00 \\
\hline Bonferroni p-values & 0.136 & 1.00 & 0.16 & 1.00 & 1.00 & 1.00 & 1.00 & 1.00 & 1.00 & 1.00 & 1.00 \\
\hline number $<-2.326$ & 0.00 & 0.00 & 18.0 & 0.00 & 0.00 & 0.00 & 0.00 & 0.00 & 0.00 & 0.00 & 0.00 \\
\hline number $-2.326>=t<-1.960$ & 0.00 & 1.00 & 12.0 & 0.00 & 0.00 & 0.00 & 0.00 & 0.00 & 2.00 & 0.00 & 0.00 \\
\hline number $-1.960>=t<-1.645$ & 0.00 & 3.00 & 2.00 & 0.00 & 0.00 & 0.00 & 0.00 & 1.00 & 2.00 & 0.00 & 0.00 \\
\hline number $-1.645>=t<-1.282$ & 0.00 & 2.00 & 17.0 & 1.00 & 8.00 & 1.00 & 0.00 & 5.00 & 2.00 & 0.00 & 0.00 \\
\hline number $-1.282>=\mathrm{t}<0$ & 0.00 & 12.0 & 51.0 & 34.0 & 88.0 & 28.0 & 0.00 & 58.0 & 40.0 & 3.00 & 0.00 \\
\hline number $0>=t<1.282$ & 0.00 & 55.0 & 5.00 & 22.0 & 9.00 & 62.0 & 70.0 & 40.0 & 51.0 & 16.0 & 106. \\
\hline number $1.282>=\mathrm{t}<1.645$ & 0.00 & 13.0 & 0.00 & 20.0 & 1.00 & 11.0 & 31.0 & 2.00 & 6.00 & 6.00 & 0.00 \\
\hline number $1.645>=t<1.960$ & 0.00 & 13.0 & 0.00 & 16.0 & 0.00 & 1.00 & 5.00 & 0.00 & 1.00 & 7.00 & 0.00 \\
\hline number $1.960>=t<2.326$ & 0.00 & 5.00 & 0.00 & 11.0 & 0.00 & 3.00 & 0.00 & 0.00 & 0.00 & 7.00 & 0.00 \\
\hline number $\quad t>=2.326$ & 106. & 1.00 & 0.00 & 2.00 & 0.00 & 0.00 & 0.00 & 0.00 & 2.00 & 67.0 & 0.00 \\
\hline $\max t$ stat & 7.01 & 2.72 & 0.677 & 2.56 & 1.32 & 2.30 & 1.80 & 1.39 & 3.33 & 23.0 & 0.46 \\
\hline Bonferroni p-values & 0.00 & 0.37 & 1.00 & 0.59 & 1.00 & 1.00 & 1.00 & 1.00 & 0.05 & 0.00 & 1.00 \\
\hline
\end{tabular}

Panel B: Cross-sectional Distribution of Coefficients

$\begin{array}{llllllllllllll}\sigma_{\mathrm{m}}^{2} & \delta_{\mathrm{C}} & \delta_{\mathrm{TB}} & \delta_{\mathrm{DP}} & \delta_{\mathrm{TERM}} & \delta_{\mathrm{JAN}} & \mathrm{R}^{2} & \gamma & \alpha_{\mathrm{p}} & \mathrm{h} & \rho^{2}\end{array}$

Mean values

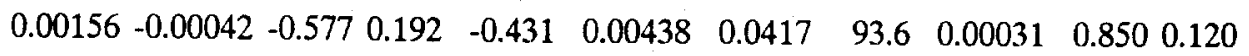

lower decile values

lower quartile values

median values

upper quartile values

upper decile values

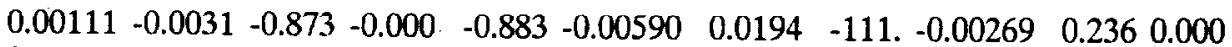

$\begin{array}{lllllllllll}0.00123 & 0.00143 & -0.721 & -0.000 & -0.623 & -0.00024 & 0.0294 & -37.9 & -0.00103 & 0.518 & 0.000\end{array}$

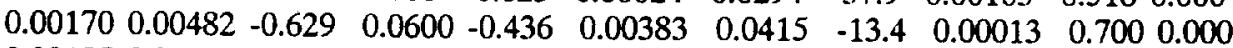

$\begin{array}{lllllllllll}0.00185 & 0.00732 & -0.425 & 0.0975 & -0.294 & 0.00991 & 0.0484 & 33.1 & 0.00134 & 0.894 & 0.000\end{array}$

$\begin{array}{lllllllllll}0.00190 & 0.00875 & -0.296 & 0.149 & -0.121 & 0.0146 & 0.0645 & 228 & 0.00298 & 1.09 & 0.818\end{array}$

Panel C: Cross-sectional Correlation of Coefficients

\begin{tabular}{|c|c|c|c|c|c|c|c|c|c|c|}
\hline$\sigma_{\mathrm{m}}^{2}$ & $\delta_{C}$ & $\delta_{\mathrm{TB}}$ & $\delta_{\mathrm{DP}}$ & $\delta_{\text {TERM }}$ & $\delta_{\text {JAN }}$ & $\mathrm{R}^{2}$ & $V$ & $\alpha_{p}$ & $\mathrm{~h}$ & $\rho^{2}$ \\
\hline 1.0 & $\begin{array}{l}-0.12 \\
1.0\end{array}$ & $\begin{array}{l}-0.62 \\
-0.057 \\
1.0\end{array}$ & $\begin{array}{l}0.20 \\
-0.99 \\
0.015 \\
1.0\end{array}$ & $\begin{array}{c}-0.21 \\
-0.68 \\
0.61 \\
0.63 \\
1.0\end{array}$ & $\begin{array}{l}0.46 \\
0.015 \\
0.072 \\
0.032 \\
0.031 \\
1.0\end{array}$ & $\begin{array}{c}0.53 \\
-0.35 \\
-0.78 \\
0.37 \\
-0.24 \\
0.037 \\
1.0\end{array}$ & $\begin{array}{c}-0.14 \\
0.14 \\
0.024 \\
-0.15 \\
-0.095 \\
-0.045 \\
-0.066 \\
1.0\end{array}$ & $\begin{array}{l}-0.13 \\
0.19 \\
-0.051 \\
-0.21 \\
-0.076 \\
-0.32 \\
-0.0098 \\
-0.16 \\
1.0\end{array}$ & $\begin{array}{c}-0.27 \\
0.10 \\
0.20 \\
-0.11 \\
0.070 \\
-0.14 \\
-0.29 \\
-0.045 \\
0.15 \\
1.0\end{array}$ & $\begin{array}{c}0.097 \\
-0.058 \\
0.12 \\
0.053 \\
0.11 \\
0.15 \\
-0.056 \\
0.16 \\
-0.057 \\
-0.077 \\
1.0\end{array}$ \\
\hline
\end{tabular}




\section{Table 6}

Cross-sectional Regressions of Conditional Market Timing Modei Paremeters

The system (9) is estimated for each asset allocator fund with at least 60 return observations. The benchmark return is the Standard and Poors 500 index. $\mathrm{K}$ is the parameter which measures the quality of the manager's market timing signal, $\gamma$ is the coefficient of risk aversion, and $h$ is the benchmark preference parameter. The table shows cross-sectional regressions for (1) the sample average of the portfolio weight in stocks, Mean $\left(\mathrm{x}_{\mathrm{s}}\right)$, and (2) the sample standard deviation of the weight in stocks taken across the quarters for which the data are available for a given fund, $\mathrm{SD}\left(\mathrm{x}_{\mathrm{s}}\right)$. The three parameter estimates are the independent variables in the cross-sectional regressions. Ordinary T-ratios are shown in parentheses. The number of cross-sectional observations is 102 .

Model Parameter Values:

$$
r^{-1} \quad \mathrm{~K}^{2} \quad \mathrm{~h}
$$

$\operatorname{Mean}\left(\mathrm{x}_{\mathbf{s}}\right)$

103.7

0.26

(0.73)

19.4

$\mathrm{SD}\left(\mathrm{x}_{\mathrm{s}}\right)$
0.32

(0.21)
0.43

(2.34)
$-0.50$

$(-0.17)$ 
Table 7

Additional Tests of Market Timing Ability

Panel A presents estimates of the regression $r_{m, s+1}=\lambda_{L i}+\lambda_{2, i} \Delta X_{i, s}+\varepsilon_{i,+1}$, where $r_{m, s+1}$ is either the one-month, two-month, or three-month ahead cumulative excess return on the S\&P 500 index and $\Delta X_{i s}$ is the change in fractional equity holdings for fund $i$ from quarter $t-1$ to $t$. The tests are based on the 93 funds that have sufficient data for the individual regression estimation.

Panel B presents estimates of the regression $r_{m,+1}=\lambda_{L, i}+\lambda_{2 j} \Delta X_{i, t}+\lambda_{3, j} Z_{t}+\varepsilon_{i, s+1}$, where $r_{m,+1}$ is either the onemonth, two-month, or three-month ahead cumulative excess return on the S\&P 500 index, $\Delta X_{i,}$ is the change in percentage equity holdings for fund $i$ from quarter $t-l$ to $t$, and $Z_{\mathrm{t}}$ is the set of instruments for for quarter $t$. The tests are based on the 78 funds that have sufficient data for the individual regression estimation. The data are quarterly from $1992 \mathrm{Q} 1-1995 \mathrm{Q} 1$.

Panel A

\begin{tabular}{lcc}
\hline Specification & $\begin{array}{c}\text { Pooled } \\
\text { regression }\end{array}$ & $\begin{array}{c}\text { Individual } \\
\text { regressions }\end{array}$ \\
& $\begin{array}{c}\lambda_{2} \\
\text { (t-stat) }\end{array}$ & $\begin{array}{c}\text { Mean } \lambda_{2} \\
\text { (Mean } \\
\text { t-stat) }\end{array}$ \\
\hline 1-month & -0.01970 & -0.0506 \\
S\&P 500 & $(-2.29)$ & $(-0.37)$ \\
2-month & -0.01250 & -0.0303 \\
S\&P 500 & $(-0.99)$ & $(-0.10)$ \\
3-month & -0.03332 & -0.0667 \\
S\&P 500 & $(-2.91)$ & $(-0.60)$ \\
\hline
\end{tabular}

Panel B

\begin{tabular}{lcc}
\hline & $\begin{array}{c}\text { Pooled } \\
\text { regression }\end{array}$ & $\begin{array}{c}\text { Individual } \\
\text { regressions }\end{array}$ \\
Specification & $\begin{array}{c}\lambda_{2} \\
(t-s t a t)\end{array}$ & $\begin{array}{c}\text { Mean } \lambda_{2} \\
\text { (Mean } \\
\text { t-stat) }\end{array}$ \\
\hline 1-month & -0.00504 & -0.1769 \\
S\&P 500 & $(1.29)$ & $(0.34)$ \\
2-month & 0.01093 & -0.1323 \\
S\&P 500 & $(1.41)$ & $(-0.03)$ \\
3-month & 0.00469 & -0.0210 \\
S\&P 500 & $(1.76)$ & $(-0.61)$ \\
\hline
\end{tabular}

